Portland State University

PDXScholar

$12-10-1991$

\title{
Effects of Conalbumin Bound Iron on the Growth of Salmonella paratyphi $B$ and Salmonella thompson
}

John Nicholas Mason

Portland State University

Follow this and additional works at: https://pdxscholar.library.pdx.edu/open_access_etds

Part of the Bacteriology Commons, and the Biology Commons Let us know how access to this document benefits you.

Recommended Citation

Mason, John Nicholas, "Effects of Conalbumin Bound Iron on the Growth of Salmonella paratyphi B and Salmonella thompson" (1991). Dissertations and Theses. Paper 4381.

https://doi.org/10.15760/etd.6265

This Thesis is brought to you for free and open access. It has been accepted for inclusion in Dissertations and Theses by an authorized administrator of PDXScholar. Please contact us if we can make this document more accessible: pdxscholar@pdx.edu. 
AN ABSTRACT OF THE THESIS OF John Nicholas Mason for the Master of Science in Biology presented December 10, 1991.

Title: Effects of Conalbumin Bound Iron on the Growth of Salmonella paratyphi B and Salmonella thompson.

\section{APPROVED BY THE MEMBERS OF THE THESIS COMMITTEE:}

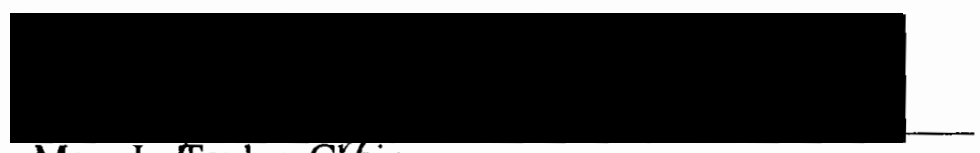

$$
\text { Mary L..Taylor, Cbair }
$$

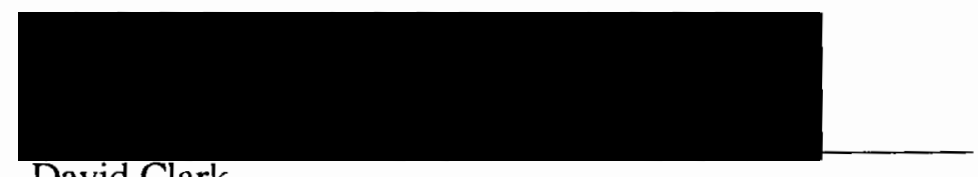

David Clark
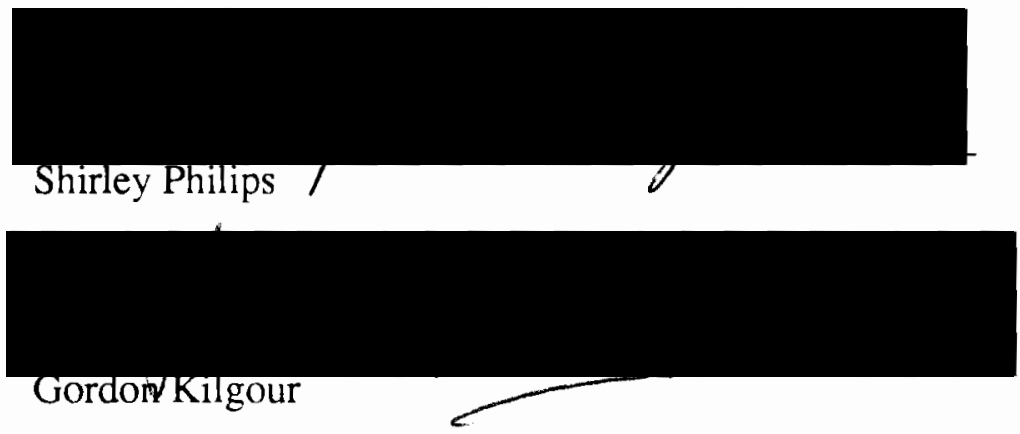

I have investigated the possibility that specific conalbumin (ovotransferrin) iron saturation levels enable less virulent strains of Salmonella to become more virulent. Iron starved cells of two pathogenic Salmonella strains, $S$, paratyphi $B$ var. java and $S$. thompson, were cultured in iron limited media at 3 different iron conalbumin saturation levels. Results indicate that strains differ significantly at both low and high iron saturation conalbumin. These differences depict a growth advantage for $S$. paratyphi $B$ which correlates with reports by the Centers for Disease Control that $S$. paratyphi $B$ was 3 times 
more frequent in blood isolates than $S$. thompson. The ability to use protein bound iron may account for the higher involvment of S. paratyphi $B$ in bacteremia. 
EFFECTS OF CONALBUMIN BOUND IRON ON THE GROWTH OF SALMONELLA PARATYPHI B AND SALMONELLA THOMPSON

\author{
by \\ JOHN NICHOLAS MASON
}

A thesis submitted in partial fulfillment of

the requirements for the degree of

MASTER OF SCIENCE

in

BIOLOGY

Portland State University

1992 


\section{TO THE OFFICE OF GRADUATE STUDIES:}

The members of the Committee approve the dissertation of John Nicholas Mason presented December 10, 1991.

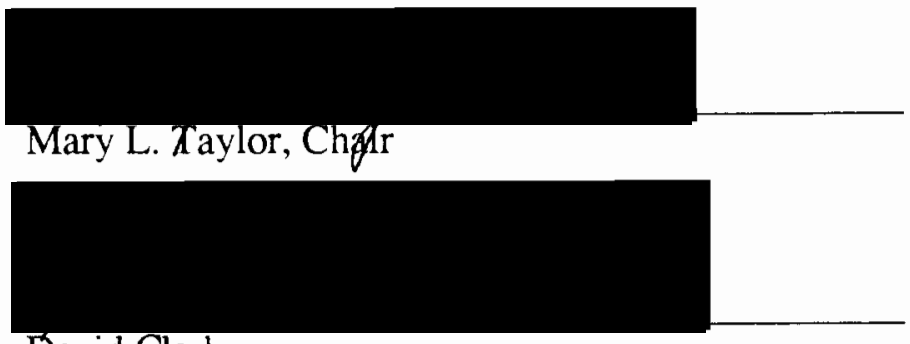

David Clark

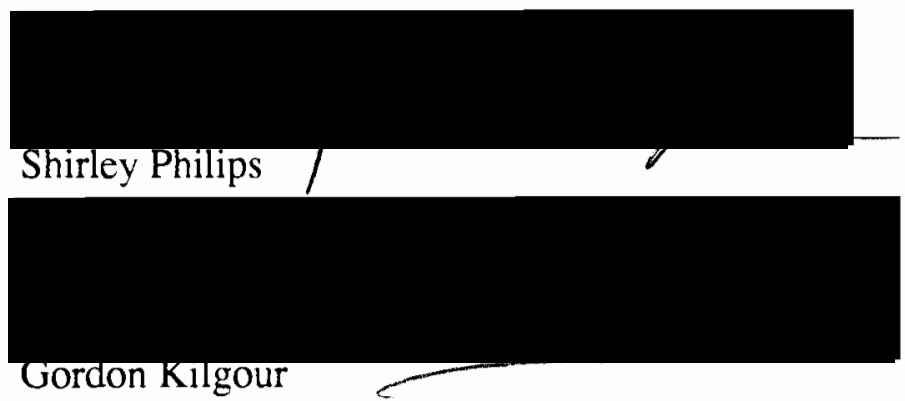

\section{APPROVED:}

Robert O. Tinnin, Chair, Department of Biology

C. William Savery, Interim Vice Provost for Graduate Studies and Research 


\section{ACKNOWLEDGEMENTS}

I wish to express my sincere gratitude to Dr. Mary Taylor for providing the education and freedom to pursue my research desires. I am also indebted to her faith in my abilities throughout this endeavor. 


\section{CONTENTS}

PAGE

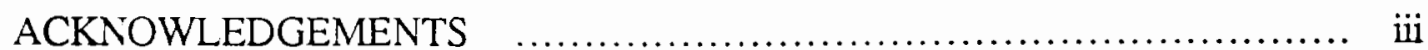

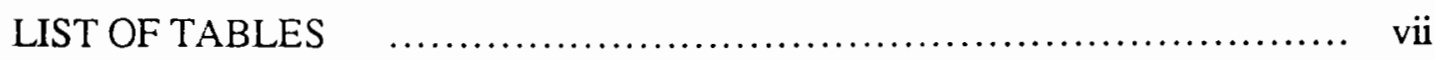

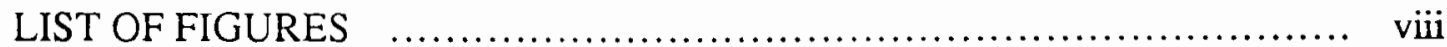

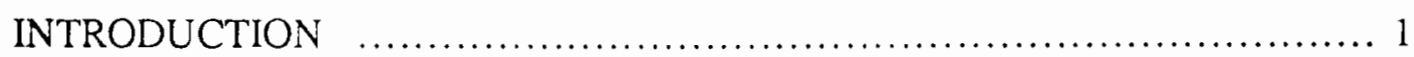

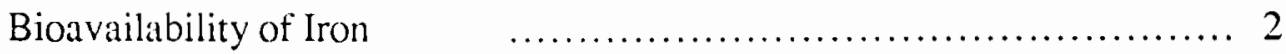

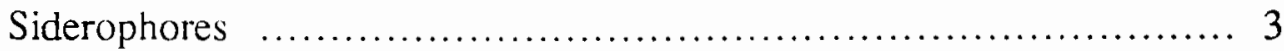

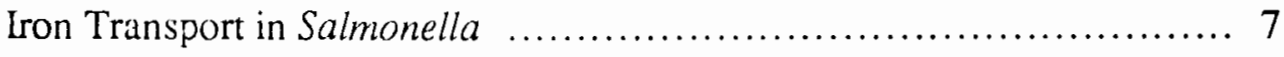

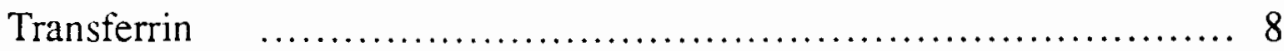

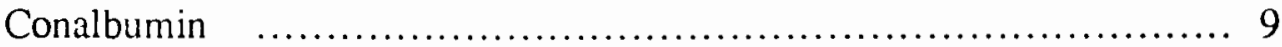

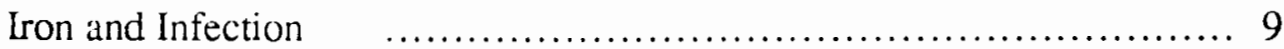

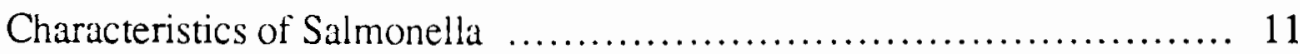

Classification

Pathogenicity of Salmonella

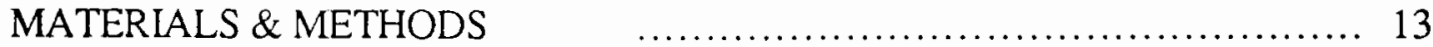

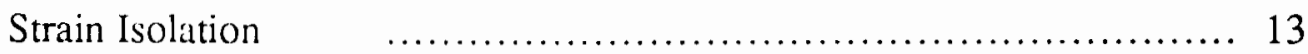

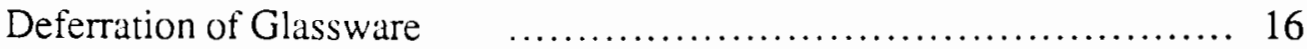

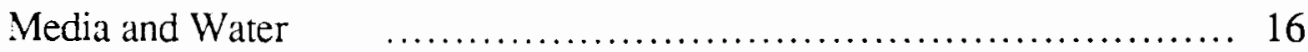

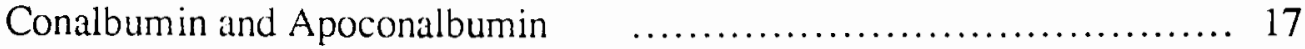

Glucose Concentration of Medium A $\quad \ldots \ldots \ldots \ldots \ldots \ldots \ldots \ldots \ldots, 18$

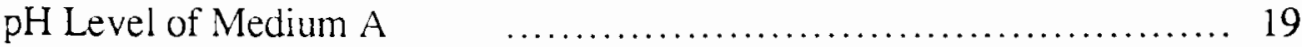


Iron Assessment $\quad$......................................... 19

Deferration of Media $\quad$............................................... 20

Reduction of Useable Intracellular Iron Stores $\quad \ldots \ldots \ldots \ldots \ldots \ldots \ldots . . \ldots 21$

Ability to Sequester Iron from Conalbumin $\quad \ldots \ldots \ldots \ldots \ldots \ldots \ldots \ldots \ldots . \ldots . \ldots 22$

Ability to Sequester Iron from Conalbumin at $\mathrm{pH} 7.0 \quad \ldots \ldots \ldots \ldots . .23$

Comparison of Strain Abilities to Use Conalbumin-Bound-Iron and

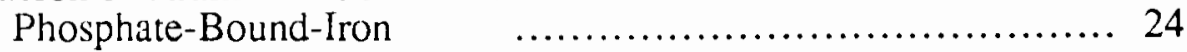

Treatment Concentrations of Iron-Saturated Conalbumin Added Near

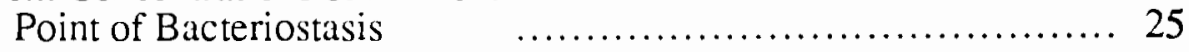

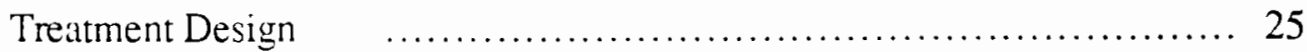

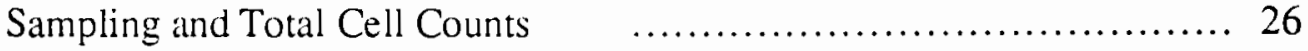

Statistical Analysis $\quad$......................................... 27

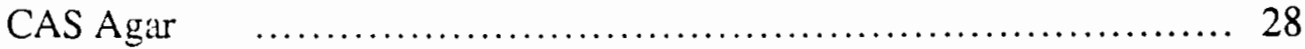

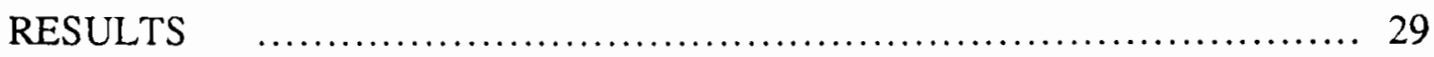

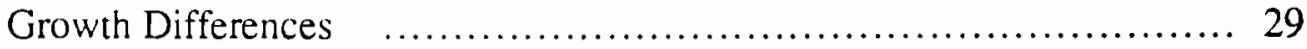

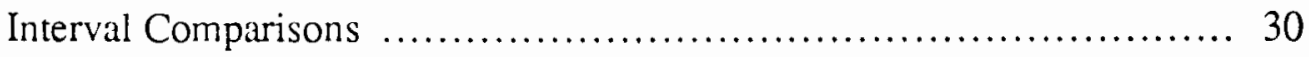

Apoconalbumin Induced Bacteriostasis .................................. 32

Growth Response to Phosphate-Bound-Iron \& Conalbumin-Bound-Iron 33

Siderophore Detection $\quad$.................................... 35

Change in Cell Morphology Under Iron Stress $\quad$................... 35

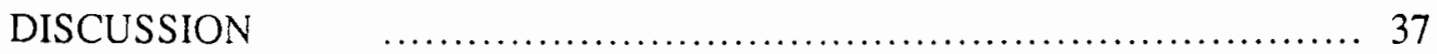

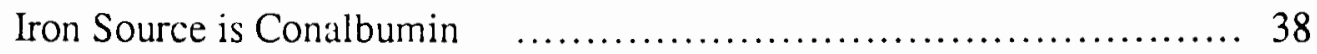

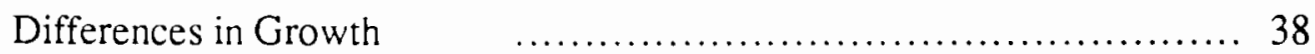

Growth Advantage of S. paratyphi $B \quad \ldots \ldots \ldots \ldots \ldots \ldots \ldots \ldots \ldots . \ldots . \ldots . \ldots 39$

Correlation of Higher Incidence of Blood Isolates to More Efficient Conalbumin Utilization 
Sampling and Counting

SUMMARY \& CONCLUSION

Summary

Conclusion

REFERENCES

\section{APPENDIX}

A PROCEDURE FOR DEFERRATION OF MEDIA SOLUTIONS .. 49

B DATA AND ANALYSIS 


\section{LIST OF TABLES}

Verified Locations of Aerobactin Genes in Salmonella Serotypes ... 8

II

III

IV

V

VI

VII

VIII

IX

XII

XIII

Salmonella Subspecies Groups 11

Results of Biochemical Tests Used To Identify Genus Salmonella . 13

Results of Biochemical Tests Performed By O.S.P.H.L at 24Hrs. 14

Results of Serotyping Tests

Media Formulations

Stock Solution Formulations 18

Solution and Media Iron Contents as Measured Using Atomic Absorption Spectrophotometer

Iron-Saturated Conalbumin Treatment Concentration Per $15 \mathrm{Ml}$ of Medium A

Significance of Difference of Growth as Determined by

Wilcoxon Signed Rank Test

Significance of Difference of Interval Growth as

Determined by Wilcoxon Signed Rank Test 


\section{LIST OF FIGURES}

FIGURE

PAGE

1. Siderophore structures 5

2. Buffering capacity of Medium A without apoconalbumin ........ 19

3. Apoconalbumin induced bacteriostasis 22

4. Ability to sequester conalbumin bound iron 23

5. Removal of conalbumin bound iron at $\mathrm{pH} 7.0$ 24

6. Growth comparison of strains

7. Growth in deferrated Medium $A$ without apoconalbumin added.... 32

8. Growth in deferrated Medium A with apoconalbumin.

9. Comparison of final growth using phosphate-bound iron with conalbumin 


\section{INTRODUCTION}

Iron is essential to most living organisms on Earth. As a transition metal, it possesses the ability to efficiently receive and donate electrons. This rich and subtle property is thought to explain why molecular evolution has made iron the element of choice for a wide range of biological functions (1).

Although iron has the ability to bind with appropriate macromolecules to form structures such as heme used for transport of oxygen in animals, iron also plays a multitude of roles in many systems crucial to the survival of procaryotic organisms. Cell composition, morphology, intermediate metabolism, synthesis of metabolic products, enzymatic activities (catalase, peroxidase, nitrogenase, etc.) as well as microbial virulence, are but a few of the many procaryotic features for which iron is essential (2).

When assessing the importance of iron in bacteria, it is important to realize that the iron concentration required for maximal growth may not be the same that is necessary, or optimal, for controlling the synthesis of secondary microbial products. For example, toxins have been shown to be produced by Clostridium sp. when iron levels are below that necessary for optimal growth.

In humans, iron is moved to and among cells by the plasma protein transferrin. Normally, this protein is between 25 and 35 percent saturated with iron (4). However, in neonates between 0 and 30 days, its synthesis is inadequate to accommodate iron supplements when given in excess $(5,6)$. Thus, the administration of iron to neonates increases the risk that abnormally high transferrin saturation levels will occur. 
Numerous studies have correlated elevated levels of transferrin iron saturation to increased Salmonella infection $(7,8,9)$. It has been suggested that higher saturation levels enable what are normally considered to be less virulent strains of Salmonella to become more virulent (10). However, the question remains as to whether this rise in virulence is due mostly to differences in the efficiency of use and/or sequestering of iron from transferrin. Evidence suggests that Salmonella siderophores are responsible for the removal of iron from transferrin (11). In recent years, much has been accomplished concerning the membrane transport proteins and structural characteristics of siderophores in this genus. By comparison, however, relatively little has been done to elucidate the differences between strain abilities in use and/or sequester of iron from transferrin.

The primary objective of this study has been to determine whether the generation times of two known pathogenic strains of Salmonella vary significantly within treatments containing different concentrations of conalbumin (ovotransferrin).

\section{BIOAVAILABILITY OF IRON}

The valence electrons of iron belong to the $3 \mathrm{~d}$ subshell. Depending on the element, as many as 10 electrons may occupy this subshell, two in each of the five orbitals. A maximum of 8 electrons can be retained in the $3 d$ subshell of iron. When this condition occurs, the oxidation state of iron is said to be neutral (12).

According to Hund's rule, the most stable arrangement of an element will occur when all the electrons in its outermost subshell are at their lowest possible energy states. For iron this condition exists at an oxidation state of +3 , or when each of the five orbitals of the $3 \mathrm{~d}$ subshell have just one electron.

Under typical biological conditions, oxidation states other than $\mathrm{Fe}^{+2}$ (ferrous) and $\mathrm{Fe}^{+3}$ (ferric) are highly unusual. To obtain greater or lower oxidation states, special 
chemical environments are usually required (13). Except for $\mathrm{Fe}^{+4}$ or $\mathrm{Fe}^{+5}$ in peroxidases, no evidence exists for the involvment of iron in biological environments at oxidation states other than +2 and +3 . Furthermore, it is only in these states that the element is stable in aqueous solution (14).

Under aqueous conditions the nature of iron is determined by the $\mathrm{pH}$ of its solution. At a $\mathrm{pH}$ of 2 or less, iron binds with water to form $\mathrm{Fe}\left(\mathrm{H}_{2} \mathrm{O}\right)_{6}{ }^{+3}$. If the $\mathrm{pH}$ is raised, protons begin dissociating to form various species of ferric hydroxide. These species have a solubility product constant between $10^{-36}$ and $10^{-38}$ (14). Thus, the solubility of hydroxy iron species is extremely limited $\left(10^{-18} \mathrm{M} \mathrm{Fe}\right)$ when at physiological $\mathrm{pH}(15)$.

Increasing the $\mathrm{pH}$ of a growth media may cause oxygen ligands of phosphates and phenols to form highly insoluble polymers with $\mathrm{Fe}^{+3}$. In addition, it should be noted that the ionic radius of $\mathrm{Fe}^{+2}$ and $\mathrm{Fe}^{+3}$ differ, being $0.83 \mathrm{~A}$ and $0.67 \mathrm{~A}$ respectively. Thus, their affinities for ligands differ as well. This is exemplified by the fact that only $\mathrm{Fe}^{+3}$ binds with oxygen ligands (16).

\section{SIDEROPHORES}

Since the evolution of an oxidizing atmosphere on Earth, iron has become a limiting nutrient due to its mineralization and precipitation as ferric hydroxide in water (17). This phenomenon is thought to have encouraged microorganisms to evolve organic compounds of low molecular weight (500-1000 daltons) for solubilizing iron. Collectively, these compounds are called siderophores.

Siderophores are characterized by tremendous formation constants between $10^{23}$ and $10^{52}$. Until recently they were grouped into seven families: ferrichromes, ferrioxamines, fusarinines, rhodotorulic acids, enterochelins, mycobactins, and aerobactins (18). Ferrichromes, ferrioxamines, fusarinines and rodotorulic acid are produced exclusively by 
fungi. The remaining families, enterochelin, mycobactin, and aerobactin, are products of eubacteria. Hydroxamate ligands prevail in all these families except enterochelin, which contains catecholes. These catecholes allow $\mathrm{Fe}^{+3}$ to bind with a formation constant 7-12 log units larger than hydroxamates (19).

Of the siderophore families found in bacteria, only the lipid soluble mycobactin (found in certain strains of Mycobacterium, Nocardia, and Rhodoococcus) is membrane bound (20). Enterochelin and aerobactin are non-lipid soluble and thus non-membrane bound. These siderophores, widespread among aerobic bacteria, are readily excreted into the environment (21).

As shown in Figure 1a, the enterobactin molecule is a trimer with monomers of 2,3dihydroxybenzene bound through a carbonyl group to the adjacent serine; three of these serines are bound in a ring. Three catechol groups coordinate to $\mathrm{Fe}^{+3}$, releasing 6 protons and forming a hexacoordinate octahedral anionic complex as shown in Figure 1c. This structure produces a net charge of minus three and has a molecular weight of 719 daltons (22).

Enterochelin undergoes a drastic conformational change during metal complexation. The bacterial membrane receptors recognize only the metal-laden form. Once attached, a series of membrane proteins transport ferric-enterochelin into the cell cytoplasm. The enzyme ferric enterochelase then splits the hexacoordinate octahedral complex, lowering the formation constant of the siderophore so that cytoplasmic reduction can make the iron available to the cell $(24,25)$.

In aerobactin (Figure 1b) two hydroxamate-containing sidearms connect through amide bonds to the terminal carboxyl of a citric acid residue. The coordination of the ferric ion is provided by the four hydroxamate oxygens as well as the carbonyl and hydroxyl oxygens from the citrate moiety (23). 
A.

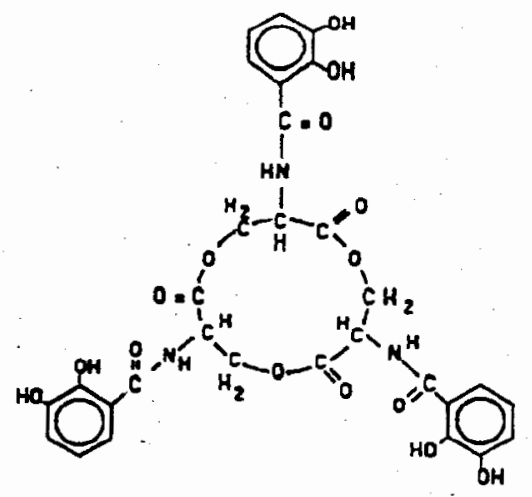

a Taken from Payne (21).

B .

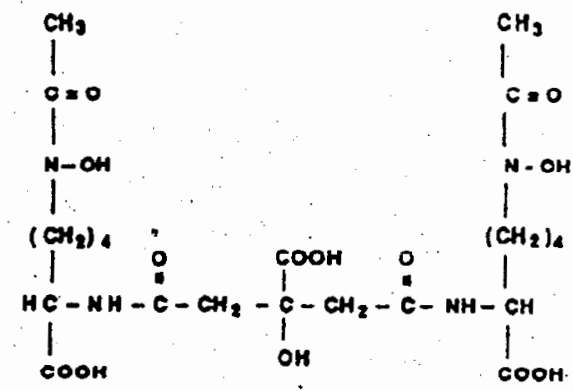

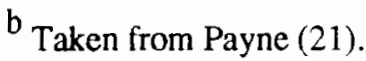

C.

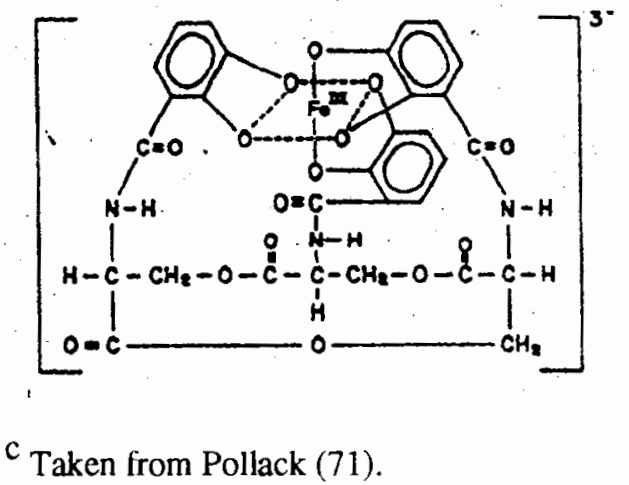

Figure 1. Siderophore structures. A) structure of catechol siderophore enterochelin B) Structure of hydroxamate siderophore aerobactin. C) Structure of ferric enterochelin. 
When complexed with $\mathrm{Fe}^{+3}$ aerobactin, like enterochelin, is recognized by a membrane receptor. However, unlike enterochelin, once the membrane proteins have transported the molecule into the cytoplasm aerobactin releases the ferric ion without enzymatic degradation. This iron-free aerobactin may then be re-excreted to scavenge for more iron (26).

The mechanism that bacteria use to acquire and transport iron depends on the iron concentration in their environment. When iron is abundant, it is believed to enter the cell by a low affinity transport system. While not yet characterized, this non-energy dependent system is thought to involve a membrane carrier. It is termed low affinity because high iron concentrations (approx. $10 \mu \mathrm{M}$ for Escherichia coli) are required to sustain normal bacterial growth (27).

In $E$. coli when intracellular iron concentrations of a cell rise above $1.6 \times 10^{-17} \mathrm{M} \mathrm{Fe}$ it acts as a corepressor with the ferric uptake regulation (Fur) protein. The Fur protein is responsible for regulating the synthesis of both aerobactin and enterochelin. Thus, lowiron environments are thought to reduce the intracellular iron concentration, which causes de-repression of iron boxes by the Fur protein and allows the subsequent synthesis of aerobactin and/or enterochelin $(28,29)$.

Bacteria must be able to take up iron to survive and multiply in the human body. Since organic iron carriers in the body (transferrin, lactoferrin, or hemoglobin) limit iron availability to $10^{-18} \mathrm{M}$, the efficiency of the low affinity system is not adequate to maintain normal growth of bacteria (67). Under conditions present in the blood vessel or tissues, iron is thought to be aquired by one or more of the following: 1) direct utilization of transferrin, in which bacterial cell surface receptors specific for transferrin, bind and somehow remove the complexed iron; 2) transferrin (or hemoglobin) degradation by specific enzyme(s), causing the release of iron and subsequent uptake through the low 
affinity system; or 3) the removal and uptake of iron from transferrin by enterochelin or aerobactin.

Reports of direct use of iron from transferrin are uncommon (30). Enzymatic degradation of hemoglobin and transferrin have been reported only for Neisseria, Haemophilus, Staphylococcus and Streptococcus, as well as a limited number of enterics (31). However, reports of enteric bacteria that obtain iron from transferrin by means of siderophores are numerous (31).

\section{IRON TRANSPORT IN SALMONELLA}

While the enterochelin gene locus is thought to be common on the chromosome of Salmonella, the aerobactin gene locus was not identified until recently (32). Early isolations showed the aerobactin gene to be only plasmid borne, but more recent studies have verified its location on the chromosomal genome in some strains and chromosome and plasmid in others (33). Furthermore, aerobactin genes are flanked by insertion sequences, which suggests that they may act as transposons (34). Table I lists the strains in which the aerobactin gene locus has been identified and shows whether the gene is plasmid and/or chromosome borne.

Despite a higher formation constant in vivo, aerobactin appears to be the siderophore of choice for removing iron from transferrin (35). Two plausible explanations are: a) the transport of enterochelin may be inhibited if enterochelin complexes more readily with plasma proteins than does aerobactin(36) or b) enterochelin, produced by the body's normal intestinal flora, could be antigenic and, therefore, may result in immunoglobulinenterochelin complexes which are not transported into the cell (37). 
TABLE I

\section{VERIFIED LOCATIONS OF AEROBACTIN GENES ${ }^{\text {a }}$ \\ IN SALMONELLA SEROTYPES}

\begin{tabular}{lcc}
\hline Strain & Plasmid & Chromosome \\
\hline S. arizona & + & + \\
S. johannesburg & + & - \\
S. typhi & + & + \\
S. wien & + & - \\
S. heildelberg & + & - \\
S. typhimurium & + & + \\
S. austin & + & + \\
S. memphis & + & + \\
\hline $\mathrm{a}_{(21,34,36)}$ & &
\end{tabular}

TRANSFERRIN

The transferrin molecule is a glycoprotein with a molecular weight of about 80,000 daltons. Like other plasma proteins, it is distributed throughout most of the extracellular fluid of the body. The function of this glycoprotein is to transport iron stored in the liver, spleen, and bone marrow to other parts of the body. The tissues responsible for synthesis of transferrin are located in the reticuloendothelial system (38).

The amount of transferrin in a typical adult varies from 1.8 to $2.6 \mathrm{mg}$ per ml of plasma (39). This amount of transferrin is sufficient to bind 25 to $40 \mu \mathrm{g}$ of iron per $\mathrm{ml}$ of plasma. A single transferrin molecule can bind two atoms of ferric iron. The binding sites for iron appear to be equal, with each involving five protein ligands and a bicarbonate ion (40). The exact means by which ferric iron binds to transferrin is still unclear.

Ferrous iron, which has a larger radius than ferric iron, is unable to attach to the oxygen ligands of transferrin. Ferrous iron, found mostly in the body's ferritin iron stores, must first be oxidized by the caeruloplasmin protein before the iron can attach to transferrin (41). 
CONALBUMIN

Conalbumin is found only in the egg white of birds. It is similar to transferrin, and nearly indistinguishable in its reaction with iron (73). Conalbumin and transferrin are similar with respect to molecular size, metal binding capacity, and chromogenic properties. However, conalbumin has a slightly higher iron stability constant, and there are some minor differences in its carbohydrate moieties (42).

Three species of conalbumin are known: (1) apoconalbumin, (2) Fe-saturated conalbumin with two $\mathrm{Fe}^{+3}$, and (3) conalbumin with one $\mathrm{Fe}^{+3}$. The overall reaction of conalbumin with iron can best be described by the equation (43):

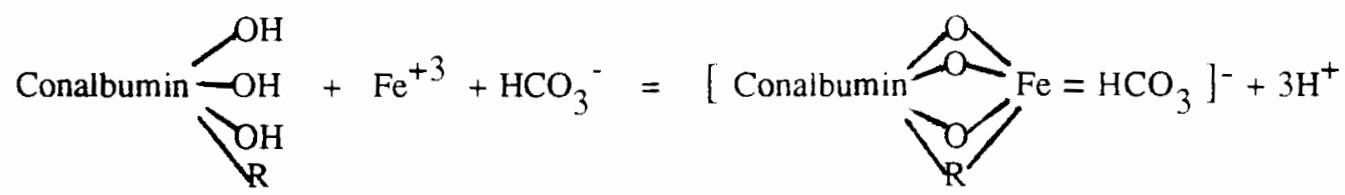

Studies have shown a constant maximal adsorption for equivalent amounts of the protein and iron between $\mathrm{pH} 6.0$ and 11.0, indicating that dissociation of iron does not occur within this range (44). Enterochelin and aerobactin are less efficient at removing iron from conalbumin than from transferrin. Enterochelin is more efficient than aerobactin at removing iron from transferrin (45).

\section{IRON AND INFECTION}

A number of studies have correlated iron therapy to increased bacteremia. Bullen et al. (46) observed that when Guinea pigs were given Clostridium welchii and 260 units of antitoxin intramuscularly, the organisms continued to multiply for 4 hours, after which growth stopped and the bacteria began to die. However, if iron were given with the injection, the organisms multiplied until the animal died.

Fletcher and Goldstein (47) showed that when injected into the peritoneum of a 
mouse, E. coli 0111 grew for only 4 hours. This abrupt termination was attributed to the inability of the strain to produce enterochelin. If enterochelin was added the organism continued to grow, causing a lethal infection.

Purifoy and Lankford (48) discovered that S. typhimurium given in low doses can survive in the mouse peritoneum for several days killing only $30 \%$ of the mice. However, if the same strain of infected mice were given daily injections of $\mathrm{Fe}^{+3}$, their death rate increased from $30 \%$ to $70 \%$ (48).

Children with Kwashiorkor (who show a reduced level of transferrin synthesis) often experience low serum iron levels. As a consequence, these children are frequently subjected to iron therapy which has been shown to correspond with significantly higher death rates (51).

Normal neonates in the early weeks of life have a mild physiological hyperferremia which lasts for several weeks (49). This condition occurs because high iron storage levels result in higher than normal iron transferrin saturation levels. Such levels have been correlated with a reversal in the bacteriostatic effect of sera (8). Therefore, it is not suprising that this period of infancy is also associated with a higher occurance of clinical illness involving Salmonella infection (50).

The fact that only $30 \%$ of a normal adult's transferrin is saturated with iron suggests that unsaturated transferrin may play an important role in preventing the establishment of organisms that are poor at removing iron from transferrin. Thus, maintaining a high unsaturated transferrin level in the body may be crucial in the body's defense against certain pathogenic organisms. 


\section{CHARACTERISTICS OF SALMONELLA}

\section{Classification}

Salmonella are Gram negative, non-sporeforming rods of the family Enterobacteriaceae. The genus Salmonella formerly consisted of 3 species: S. choleraesuis, S. enteritidis, and S. typhi. However, based on recent DNA hybridization studies, all members are now classified under one species, S. enterica (52).

Despite differences in antigenic types, biochemical reactions, and geographic distributions, all serotypes are believed to have diverged from S. enterica (53). Differences have been accounted for by dividing the species into 5 subgroups (see Table II). Of the more than 2,000 serotypes in these subgroups, $90 \%$ belong to subgroup I. Further, $95 \%$ of all clinical isolates are found to be associated with subgroup I.

TABLE II

SALMONELLA SUBSPECIES GROUPS

\begin{tabular}{cccccc}
\hline Subgroup & Subgroup & Subgroup & Subgroup & Subgroup & Subgroup \\
1 & 2 & $3 \mathrm{a}$ & $3 \mathrm{~b}$ & 4 & 5 \\
enterica & salmae & arizonae & diarizonae & houtenae & bongori \\
\hline
\end{tabular}

\section{Pathogenicity of Salmonella}

Salmonella infection may occur in any of 3 distinct clinical entities: self-limiting gastroenteritis, enteric fever, or bacteremia. The most common form of expression is gastroenteritis, which may be produced by any serotype of Salmonella. While not invasive, gastroenteritis does create intestinal colitis, which is characterized by mucosa hyperemia, petechiae, and ulceration (54).

Unlike gastroenteritis, invasiveness is a characteristic of enteric fever and is typified by penetration of the mucosa and subepithelial tissue by the bacterial cells before entering into 
the lammina propria. Once in the lammina propria, the organism is phagocytized by monocytes and enters the blood stream, thus infecting the reticuloendothelial system and other organs. While most any serotype may produce this disease, S. typhi, S. paratyphi A and S. shottmuelleri (paratyphi $B$ ) are most frequently responsible.

Salmonella that infect monocytes undergo an incubation period that can last between 1 and 14 days, after which the bacteria enter the blood stream, and the disease is classified as bacteremia. Thus, bacteremia may be considered an advanced form of enteric fever. 


\section{MATERIALS AND METHODS}

\section{STRAIN ISOLATION}

Two known pathogenic strains of Salmonella were chosen: S. enterica subspecies enterica serotype paratyphi B, var. java, isolated from a patient at Emanuel Hospital in Portland, OR; and S. enterica subspecies enterica serotype thompson, obtained from a 1977 glycerol stock culture in Dr. M. Taylor's laboratory at Portland State University.

For verification, each strain was cultured on plates of SS medium (Difco) until colony uniformity was achieved. Using colonies from these plates, the biochemical tests listed in Table III were performed.

TABLE III

RESULTS OF BIOCHEMICAL TESTS USED

TO IDENTIFY GENUS SALMONELLA

\begin{tabular}{ll}
\hline Test & Result \\
Gram stain & Negative \\
Catalase & Positive \\
Oxidase & Negative \\
O/F & Oxid/Ferm \\
Urea & Negative \\
Indole & Negatve \\
Citrate & Positive \\
Glucose & Positive \\
Lactose & Negative \\
Sucrose & Negative \\
H $2 S$ & Positive
\end{tabular}


Results in Table III were found to be in agreement with those outlined in Bergey's Manual of Determinative Bacteriology for identification of bacteria belonging to the genus Salmonella (56). After tentative identification of the genus, the strains were cultured on Luria medium and transferred into glycerol for storage at minus $30^{\circ} \mathrm{C}$.

Plates containing SS medium were later streaked from these stocks and taken to the Oregon State Public Health Laboratory (O.S.P.H.L.) for confirmation of the results. The following biochemical tests (see Table IV) which verified the strains as belonging to the genus Salmonella were performed by O.S.P.H.L.

TABLE IV

RESULTS OF BIOCHEMICAL TESTS PERFORMED

BY O.S.P.H.L AT 24 HRS

\begin{tabular}{lcc}
\hline Test & paratyphi $B$ & thompson \\
TSI SL/Butt & K/AG & K/AG \\
LiA SL/Butt & K/K & $\mathrm{K} / \mathrm{K}$ \\
$\mathrm{H}_{2}$ S Butt/Paper & Pos & Pos \\
Motility & Pos & Pos \\
MR & Pos & Pos \\
Indole & Neg & Neg \\
Citrate & Pos & Pos \\
Phenylalanine & Neg & Neg \\
Na Malonate & Neg & Neg \\
Jordan's Citrate & Pos & $*$ \\
\hline K = alkali, A = acidic, G $=$ gas, ${ }^{*}$ test not run &
\end{tabular}

The strains were serotyped by O.S.P.H.L. and positively identified as S. enterica subspecies enterica serotype paratyphi B, var. java. (serotype 4,5,12:b: 1,2) and $S$. enterica subspecies enterica serotype thompson (serotype $6,7: \mathrm{k}: 1,5$ ). Results of the serological tests are shown in Table V. 
When reporting serotypes, the taxonomically correct format (according to the rules of the International Code of Nomenclature for Bacteria) is to first list the genus, then the species, subspecies and finally the serotype. However, this procedure tends to be cumbersome. To minimize confusion, the U.S. Center for Disease Control has adopted a practical and more simplified form where the organisms are reported as though the serotype were the species. This artificial form, now widely accepted in much of the world (for situations where precision is not essential) (52), has been adopted for this thesis.

TABLE $V$

RESULTS OF SEROTYPING TESTS

\begin{tabular}{cccc}
\hline $\begin{array}{c}\text { Salmonella } \mathrm{O} \\
\text { Antiserum Tested }\end{array}$ & pararyphi B & & thompson \\
Polyvalent & Pos & Pos \\
(Gr. B) Fac 4/5 & Pos & Neg \\
(Gr. C1) & 7 & Neg & Pos \\
(Gr. C2) & 8 & Neg & Neg \\
(Gr. D) & 9 & Neg & Neg
\end{tabular}

Salmonella Flagella

(H) Antiserum Tested

\begin{tabular}{|c|c|c|}
\hline 1 & Pos & $\ldots$ \\
\hline 2 & Pos & $\mathrm{Neg}$ \\
\hline 3 & $\cdots$ & Pos \\
\hline 4 & Pos & -..- \\
\hline 5 & $\cdots$ & Pos \\
\hline 6 & $\cdots$ & Neg \\
\hline 7 & Pos & Pos \\
\hline$b$ & Pos & --.-- \\
\hline $\mathrm{k}$ & $\mathrm{Neg}$ & Pos \\
\hline SP7 & $\ldots$ & $\operatorname{Pos}^{(a)}$ \\
\hline
\end{tabular}


Therefore, S. enterica subspecies enterica serotype paratyphi B, variety java and S. enterica subspecies enterica serotype thompson are hereafter referred to as $S$. paratyphi $B$ and $S$. thompson respectively.

\section{DEFERRATION OF GLASSWARE}

Evidence exists that bacterial siderophores may obtain iron from glassware (57). To eliminate this as a possible iron source, all glassware was initially brushed in a solution of Haemo Sol ${ }^{\mathrm{TM}}$ before washing in a $\mathrm{NAPCO}^{\mathrm{TM}}$ model 400 laboratory glassware dishwasher at $82^{\circ} \mathrm{C}$ followed by soaking in $1 \mathrm{~N} \mathrm{HCL}$. After 24 hours, the HCL was removed and the glassware was rinsed twice in deionized water before resoaking in $1 \mathrm{~N} \mathrm{HCL}$ for another 24 hours. After the second soaking, the glassware was rinsed twice in deionized water, refilled with deionized water, wrapped in aluminum foil, and autoclaved for 30 minutes at $130^{\circ} \mathrm{C}$ and $20 \mathrm{psi}$. Once autoclaved, the glassware was again rinsed twice in deionized water, air dried, re-wrapped in foil, and sterilized in an autoclave for 30 minutes at $130^{\circ} \mathrm{C}$ and 20 psi. The glassware was then covered and stored.

Using a Perkin-Elmer 305B Flame Atomic Adsorption Spectrophotometer, the iron contamination potential of the glassware was estimated from samples of deionized water that had been stored in the glassware for 3 days. All water was found to contain levels below the detectable range of this instrument $(3.6 \mu \mathrm{M} \mathrm{Fe})$.

\section{MEDIA AND WATER}

All water used for experiments in this thesis was obtained from a Nanopure ${ }^{T M}$ filtering system that produced deionized water having an electrical resistance of not less than $17 \mathrm{OHMS} / \mathrm{CM}^{2}$. Water was placed in deferrated glass bottles and autoclaved before being used to prepare media. 
For this study, two "low iron" media ( Medium A and Medium B) were developed (Table VI). Both media were prepared prior to each experiment from the same sterile stock solutions of which had had their iron contents measured. The same stock solutions were used for all experiments shown in this thesis. The composition of each stock solution is shown in Table VII. The two media are listed in Table VI.

\section{CONALBUMIN AND APOCONALBUMIN}

Apoconalbumin (Iron Free-Type 1) and conalbumin (Iron Complexed-Type II), both purchased from Sigma Chemical company, were used in all experiments. Apoconalbumin was included in the formulation of Medium A to decrease the efficiency of the high affinity iron transport system. Once the high affinity system was no longer able to support growth, the organisms were believed to reduce their useable intracellular iron stores. After apparent reduction of the intracellular iron stores it was considered feasible to make a direct comparison of the growth abilities of the strains to use iron from conalbumin.

TABLE VI

MEDIA FORMULATIONS

MEDIUM A

$13.4 \mathrm{ml}$ deionized $\mathrm{H}_{2} \mathrm{O}$

$0.15 \mathrm{ml} \mathrm{10X} \mathrm{Buffer}$

$37.5 \mu$ Saits B

$15 \mu$ l Glucose

$15 \mu$ Thiamine

$5 \mu 1$ Salts A

$1 \mathrm{ml} \mathrm{of} 15 \mathrm{mg} / \mathrm{ml}$ of apoconalbumin

\section{MEDIUM B}

$13.7 \mathrm{ml}$ deionized $\mathrm{H}_{2} \mathrm{O}$

$1.5 \mathrm{ml} \mathrm{Buffer}$

$37.5 \mu$ l Salts B

$12.5 \mu \mathrm{l}$ Glucose

$13.5 \mu 1$ Thiamine

$5 \mu \mathrm{l} \mathrm{Salts} \mathrm{A}$ 
TABLE VII

STOCK SOLUTION FORMULATIONS

SQLUTION

Buffer:

10X Buffer:

Salts A:

Salts B:

Glucose:

Thiamine:

\section{COMPOSITION}

$2 \mathrm{gm} \mathrm{KH}_{2} \mathrm{PO}_{4} ; 7 \mathrm{gms} \mathrm{K} \mathrm{HPO}_{4}$;

$2 \mathrm{gm}\left(\mathrm{NH}_{4}\right)_{2} \mathrm{SO}_{4} ; 1000 \mathrm{ml}$ deionized $\mathrm{H}_{2} \mathrm{O}$

$20 \mathrm{gm} \mathrm{KH}_{2} \mathrm{PO}_{4} ; 70 \mathrm{gm} \mathrm{K}_{2} \mathrm{HPO}_{4}$;

$20 \mathrm{gm}\left(\mathrm{NH}_{4}\right)_{2} \mathrm{SO}_{4} ; 1000 \mathrm{ml}$ deionized $\mathrm{H}_{2} \mathrm{O}$

$0.44 \mathrm{mg} \mathrm{ZnSO} \mathrm{Zn}_{4}-7 \mathrm{H}_{2} \mathrm{O} ; 0.40 \mathrm{mg}$

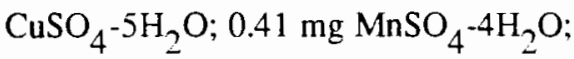

$0.42 \mathrm{mg} \mathrm{KI} ; 1000 \mathrm{ml}$ deionized $\mathrm{H}_{2} \mathrm{O}$

$0.1 \mathrm{gm} \mathrm{MgSO}_{4}-7 \mathrm{H}_{2} \mathrm{O} ; 0.01 \mathrm{gm}$

$\mathrm{CaCl}_{2}-2 \mathrm{H}_{2} \mathrm{O} ; 100 \mathrm{ml}$ deionized $\mathrm{H}_{2} \mathrm{O}$

$90.08 \mathrm{gm}$ glucose; $1000 \mathrm{ml}$ deionized $\mathrm{H}_{2} \mathrm{O}$

$1.0 \mathrm{gm} \mathrm{B} ; 1000 \mathrm{ml}$ deionized $\mathrm{H}_{2} \mathrm{O}$

\section{GLUCOSE CONCENTRATION OF MEDIUM A}

Throughout this study the $\mathrm{pH}$ of each treatment experiment remained above 6.0. Figure 2 shows the final level of growth attained when strains were allowed to completely oxidize various concentrations of glucose. For the experiments reported in this thesis, a concentration of $0.09 \mathrm{mg} / \mathrm{ml}$ of glucose was used in each of the treatment experiments. This amount of glucose provided sufficient energy to generate $2 \times 10^{8}$ cells $/ \mathrm{ml}$. Since 
growth obtained never exceeded $2 \times 10^{8}$ cells $/ \mathrm{ml}$ glucose was never a limiting factor and the $\mathrm{pH}$ of the experiment never fell below $\mathrm{pH} 6.4$.

\section{PH LEVEL OF MEDIUM A}

Figure 2 shows the final $\mathrm{pH}$ of Medium A when various levels of glucose were used as the carbon and energy source. It can be seen that despite complete oxidation of 0.09 $\mathrm{mg} / \mathrm{mi}$ of glucose, the $\mathrm{pH}$ of Medium A never dropped below 6.4. Since dissociation of iron from conalbumin does not occur until the $\mathrm{pH}$ of the medium drops below 6.0 (44) the buffering capacity of Medium A was adequate for comparing the abilities of the two different strains to use iron from conalbumin.

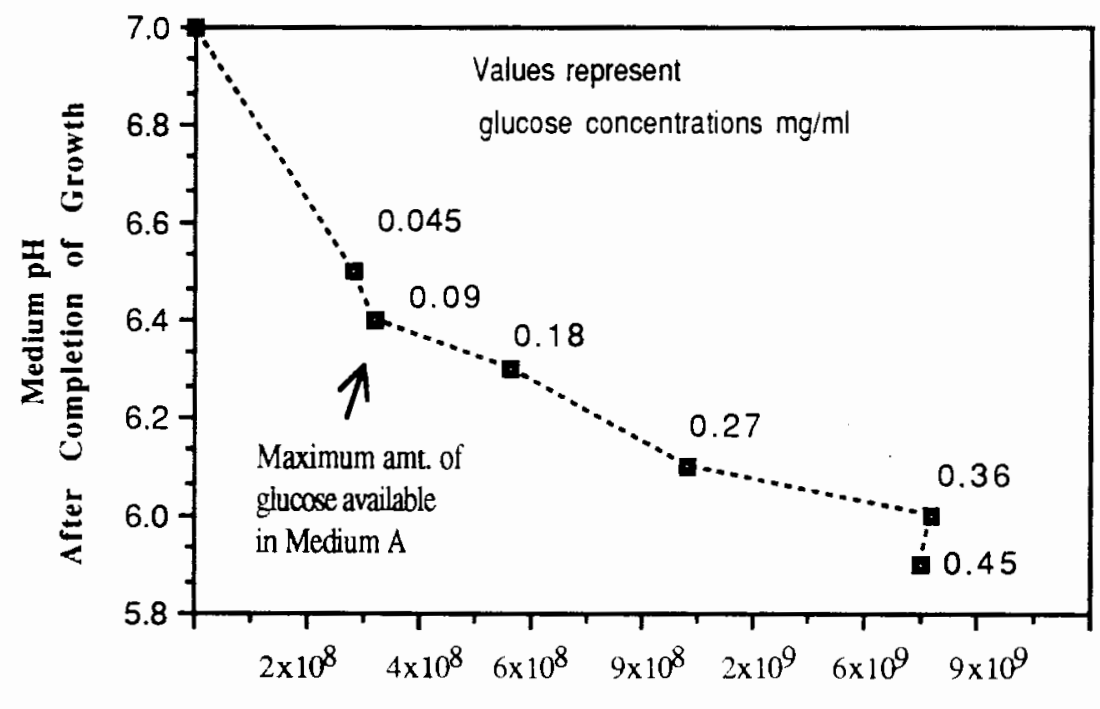

Cells $/ \mathbf{m l}$

Figure 2. Buffering capacity of Medium A without apoconalbumin.

\section{IRON ASSESSMENT}

To determine the iron content of the solutions used in this study, three flasks from each solution shown in Table VII were prepared. Ten $\mathrm{ml}$ of each solution were placed into 
three $25 \mathrm{ml}$ deferrated glass volumetric flasks containing $10 \mathrm{ml}$ of $10 \%$ nitric acid and labeled 1-3. The flasks were then sealed with glass stoppers and stored for 76 hours. For direct assessment of iron, ten samples from flask \#1 of each solution were then assayed for iron using a Perkin-Elmer 305 B Flame Atomic Absorption Spectrophotometer. Readings were averaged and reported as direct iron assessments for each solution (Table VIII). The lower limit for iron assessment by the direct method is $3.6 \mu \mathrm{M} \mathrm{Fe}$ or $0.2 \mathrm{mg} \mathrm{Fe} / \mathrm{L}$.

To account for any matrix effect, standard additions of $12 \mathrm{mg} / \mathrm{ml}$ and $24 \mathrm{mg} / \mathrm{ml}$ of iron were added to flasks \#2 and \#3 respectively for each solution. Iron assessments from all three flasks were then used to construct a matrix slope for each of the eight original solutions.

The iron content of each solution is shown in Table VIII A. Because only 3 points were used to construct the matrix adjusted curve for each solution, it was not possible to accurately plot the matrix effect. Therefore, direct results rather than matrix adjusted results were used in determining the iron content of the solutions.

\section{DEFERRATION OF MEDIA}

The iron content of Medium A and B after prepartion from the stock solutions is shown in in Table VIII Section B. The initial iron contamination of each medium (a result of iron impurities in the buffer and glucose stock solutions) was estimated to be $0.583 \mu \mathrm{M}$ Fe. This level was reduced to $0.154 \mu \mathrm{M}$ Fe by the addition of 8 -hydroxyquinoline which resulted in the formation of water-insoluble complexes with $\mathrm{Fe}^{+2}$ and $\mathrm{Fe}^{+3}$. These complexes were then solubilized by the addition of chloroform that was subsequently extracted. This process was repeated three times, after which the solutions were autoclaved and stored at $4^{\circ} \mathrm{C}$. The $\mathrm{pH}$ of Medium $\mathrm{A}$ and $\mathrm{B}$, after preparation with the solutions shown in Table VIII Section A, was between 6.9 and 7.1. This process is fully detailed in Appendix A. 
TABLE VIII

SOLUTION AND MEDIA IRON CONTENTS AS MEASURED

USING ATOMIC ABSORPTION SPECTROPHOTOMETER

A. Solution

Direct

Matrix Adjusted

$\mathrm{mg} / \mathrm{Fe} \quad \mu \mathrm{MFe}$

$\mathrm{mg} / \mathrm{Fe} \quad \mu \mathrm{MFe}$

10X Buffer (deferrated)

0.735

13.0

0.885

16.0

$1 \mathrm{X}$ Buffer (non defferrated)

0.315

6.0

0.240

4.0

Glucose (deferrated)

0.865

15.0

0.550

10.0

Salts B

0.140

3.0

0.130

2.0

Deionized $\mathrm{H}_{2} \mathrm{O}$

0.000

0.000

0.000

0.000

Thiamine

0.000

0.000

0.000

0.000

Salts A

0.000

0.000

0.000

0.000

B. Media

$\mathrm{mg} / \mathrm{Fe} \quad \mu \mathrm{M} \mathrm{Fe}$

$\mathrm{mg} / \mathrm{Fe} \quad \mu \mathrm{MFe}$

A

0.0086

0.154

0.0098

0.175

B

$0.0327 \quad 0.583$

0.0252

0.450

\section{REDUCTION OF USEABLE INTRACELLULAR IRON STORES}

To compare the direct effects of conalbumin on the growth of each strain, it was necessary to reduce the useable intracellular iron stores of each strain to assure a negligible level of background growth before testing growth at different iron-saturated conalbumin concentrations. Strains were cultured as follows: $0.1 \mathrm{ml}$ of each glycerol stock was used to inoculate separate plates of SS medium. After 9 hours, colonies from each plate were placed into separate $125 \mathrm{ml}$ flasks containing $15 \mathrm{ml}$ of Medium B. The flasks were shaken at $200 \mathrm{rpm}$ in a $37^{\circ} \mathrm{C}$ shaker for 7 hours. At the end of the 7 hours, a $10 \mu$ linoculum 
(with a cell concentration between $1 \times 10^{8} \& 2 \times 10^{8} \mathrm{cell} s / \mathrm{ml}$ ) was taken from each flask and transferred to separate $125 \mathrm{ml}$ flasks containing $15 \mathrm{ml}$ of deferrated Medium A (supplemented with $15 \mathrm{mg}$ of apoconalbumin). These flasks were then aerated at $200 \mathrm{rpm}$ and $37^{\circ} \mathrm{C}$. Figure 3 shows incubation with apoconalbumin resulted in no further increase in cell number after $51 / 2$ hours. It is asssumed the cells became bacteriostatic due to reduction of intracellular iron stores.

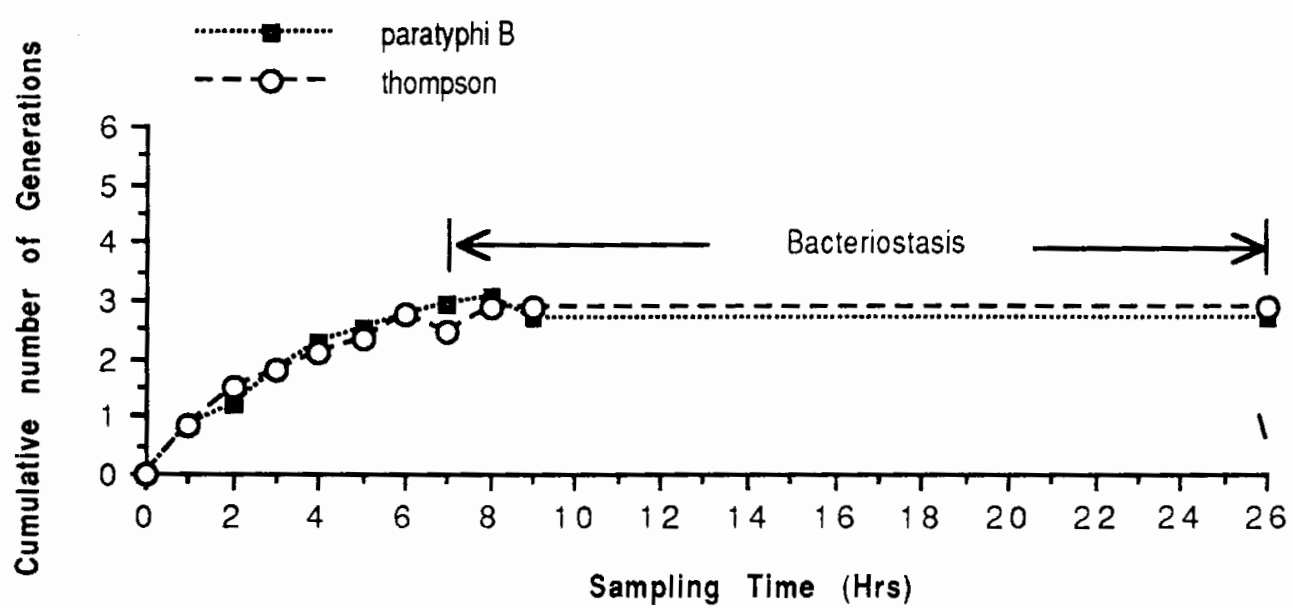

Figure 3. Apoconalbumin Induced Bacteriostasis. (Data points represent the average of 4 identical experiments).

\section{ABIIITY TO SEQUESTER IRON FROM CONALBUMIN}

To determine if the strains were capable of sequestering iron from conalbumin after being reduced of useable intracellular iron stores, $5 \mathrm{mg}$ of conalbumin was added to the flasks of each strain. The flasks were then shaken at $200 \mathrm{rpm}$ and $37^{\circ} \mathrm{C}$ and samples removed at $51 / 2,12$ and 18 hours and the total number of cells counted. As shown in Figure 4, only those flasks to which conalbumin was added had increased growth. Flasks not receiving conalbumin showed no further growth. 


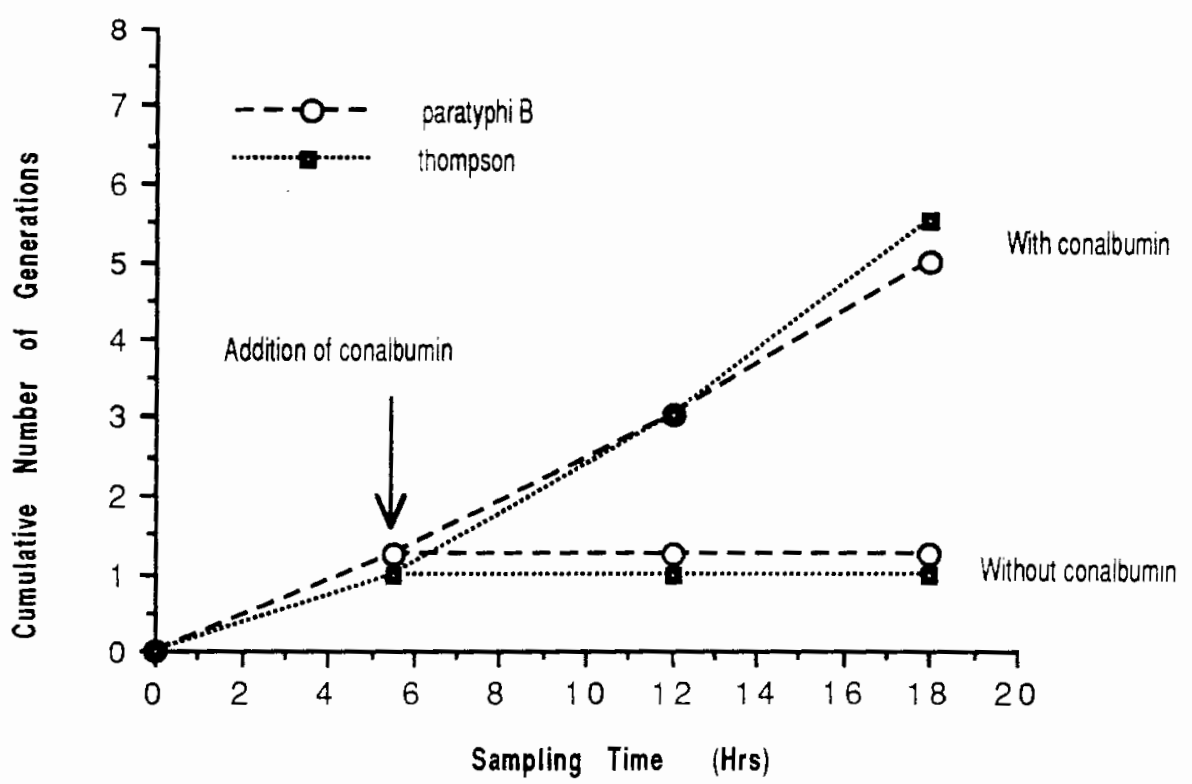

Figure 4. Ability to sequester conalbumin bound iron. (Data points represent the mean of 3 identical experiments).

\section{ABLITY TO SEQESTER IRON FROM CONALBUMIN AT PH 7.0}

Iron binds most strongly to conalbumin at $\mathrm{pH} 7.0$ (43). To verify that both strains

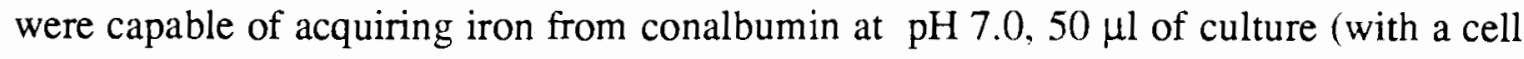
concentration between $1 \& 2 \times 10^{3}$ cells $/ \mathrm{ml}$ ) of each strain that had had their useable intracellular iron stores reduced, was placed into separate flasks with $15 \mathrm{ml}$ of deferrated Medium A. An additional $0.15 \mu \mathrm{l}$ of deferrated $10 \mathrm{X}$ buffer was added to each flask to maintain the $\mathrm{pH}$ between 7.1 and 7.0. As can be seen in Figure 5, the addition of ironsaturated conalbumin to iron starved cells resulted in the growth of both S.paratyphi $B$ and S. thompson. In the absence of iron-saturated conalbumin, the total number of cells remained constant. Thus, despite a $\mathrm{pH}$ of 7.0 , both $S$. paratyphi $B$ and $S$. thompson were still capable of removing the iron from the conalbumin. 


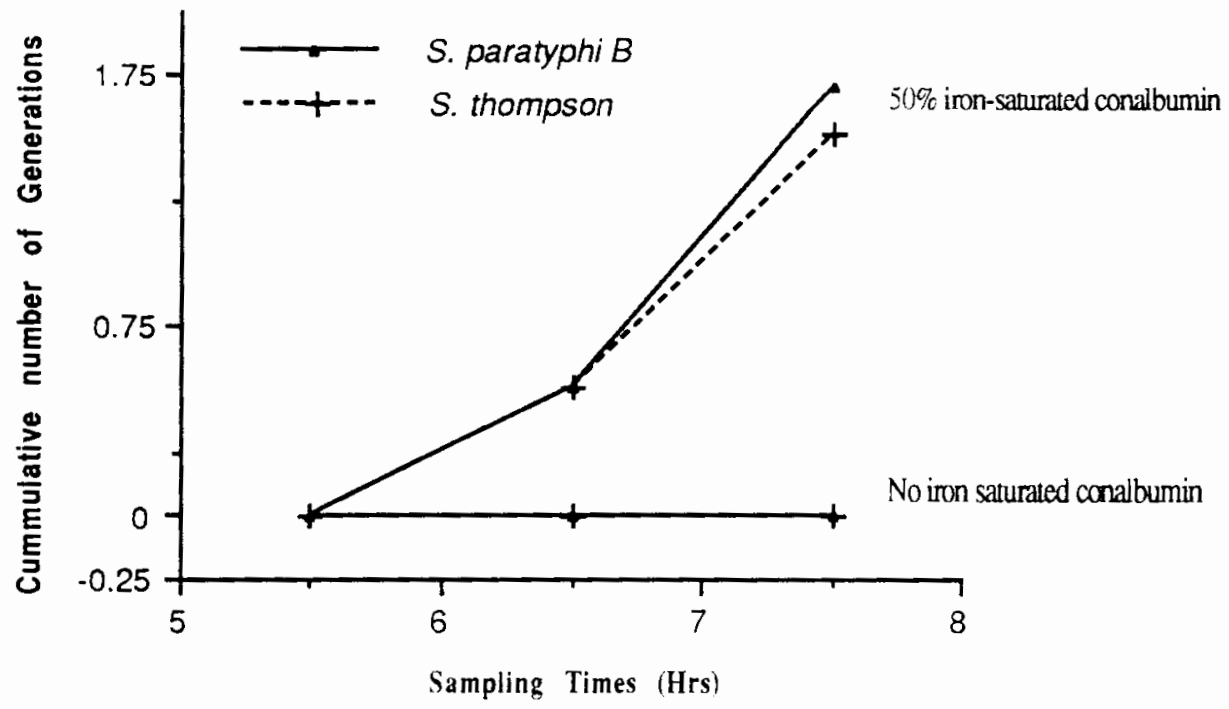

Figure 5. Removal of Conalbumin Bound Iron at pH 7.0. (Data points represent the mean of 2 identical experiments).

\section{COMPARISON OF STRAIN ABILITIES TO USE CONALBUMIN-BOUND-IRON AND PHOSPHATE-BOUND-IRON}

Phosphates of iron form when iron coordinates with oxygen atoms between $\mathrm{PO}_{4}{ }^{-3}$ anions (74). To determine if a difference existed between the abilities of the strains to obtain iron from iron-saturated conaibumin and iron bound to phosphate, a series of experiments was run in which phosphate-bound iron was added to iron starved cells in place of conalbumin bound iron.

To determine the amounts of phosphate to be added that would provide the same concentrations of iron as in differing treatment concentrations of iron-saturated conalbumin, the following rationale was used. One mole of conalbumin is equal to $80,000 \mathrm{~g}$. Thus, by adding $1 \mathrm{~g}$ of conalbumin to 1 liter of Medium $A$ the final concentration of conalbumin in Medium A was $12.5 \mu \mathrm{M}\left[\mathrm{lg} /(80,000 \mathrm{~g} /\right.$ mole $)=1.25 \times 10^{-5}$ moles conalbumin in $\left.\left.1 \mathrm{~L}\right)\right]$. Since each molecule of conalbumin binds 2 ferric iron molecules, $12.5 \mu \mathrm{M}$ iron saturated conalbumin has $25 \mu \mathrm{M}$ Fe. Thus, $5 \%$ iron-saturated conalbumin would have an iron concentration of $1.25 \mu \mathrm{M} \mathrm{Fe}\left[(0.05) \times\left(2.5 \times 10^{-5} \mathrm{M} \mathrm{Fe}\right)=1.25 \times 10^{-6} \mathrm{M} \mathrm{Fe}\right]$ and $50 \%$ 
iron-saturated conalbumin has an iron concentration of $12.5 \mu \mathrm{M} \mathrm{Fe}\left[(0.5) \times\left(2.5 \times 10^{-5} \mathrm{M}\right.\right.$ $\left.\mathrm{Fe})=12.5 \times 10^{-6} \mathrm{M} \mathrm{Fe}\right]$

The measured concentration of iron in $10 \mathrm{X}$ non-deferrated buffer is $6.0 \times 10^{-5} \mathrm{M} \mathrm{Fe}$ (Table VIII). By diluting this buffer by $1: 47$ in $\mathrm{H}_{2} \mathrm{O}$ the concentration of iron is equivalent to $1 \mathrm{~g} / \mathrm{L}$ of $5 \%$ iron-saturated conalbumin $\left[(1 / 48) \times\left(6.0 \times 10^{-5} \mathrm{M} \mathrm{Fe}\right)=1.25 \times 10^{-6} \mathrm{M}\right.$ Fe]. Thus, to each liter of Medium $A$ it was necessary to add $0.021 \mathrm{~L}(1 / 48=0.021)$ of $10 \mathrm{X}$ non-deferrated buffer to equal the amount of iron present on $1 \mathrm{~g}$ of $5 \%$ iron-saturated conalbumin in $1 \mathrm{~L}$. The amount of non-deferrated buffer that was added to equal the amount of iron on $1 \mathrm{~g}$ of $50 \%$ iron-saturated conalbumin in $1 \mathrm{~L}$ of Medium A was $0.210 \mathrm{~L}$ $[(1 / 48)(0.5)=0.210]$

\section{TREATMENT CONCENTRATIONS OF IRON-SATURATED CONALBUMIN ADDED NEAR POINT OF BACTERIOSTASIS}

To test the effect of iron-saturated conalbumin on the growth of the two different strains, we added treatment concentrations of iron-saturated conalbumin at $51 / 2$ hours, the point at which strains had their useable intracellular iron stores reduced so that growth had become negligible (Methods, Figure 3). Addition of iron-saturated conalbumin at 7 hours, the point at which bacteriostasis actually occurred, was not possible because cell clumping reduced the ability to accurately count cells.

\section{TREATMENT DESIGN}

This study was designed to test the effect of three different concentrations of ironsaturated conalbumin on the growth of each Salmonella strain. The experiment consisted of three treatments, each repeated five times. Each treatment trial consisted of an individual flask with $15 \mathrm{ml}$ of deferrated Medium A which was inoculated to give a final concentration 
of 2 to $5 \times 10^{5}$ cells $/ \mathrm{ml}$. Apoconalbumin was added to each flask and the flasks were incubated at $37^{\circ} \mathrm{C}$ at $200 \mathrm{rpms}$ for $51 / 2 \mathrm{hrs}$ to reduced the useable internal iron stores. At $51 / 2 \mathrm{hrs}$ an additional $15 \mathrm{mg}$ of apoconalbumin was added to Treatment 1 . A mixture of $1.5 \mathrm{mg}$ of conalbumin and $13.5 \mathrm{mg}$ of apoconalbumin was added to Treatment 2 to give a $5 \%$ iron-saturated conalbumin mixture. Treatment 3 was supplemented with $15 \mathrm{mg}$ of conalbumin to give $50 \%$ iron-saturated conalbumin mixture. The conditions for each treatment are summarized in Table IX.

\section{TABLE IX}

IRON-SATURATED CONALBUMIN TREATMENT

CONCENTRATION PER 15 ML OF MEDIUM A

\begin{tabular}{|c|c|c|c|c|c|}
\hline \multirow{2}{*}{ Treatment } & \multirow{2}{*}{$\begin{array}{l}\text { Added at } 0 \mathrm{hrs} \\
\text { Apo-ca } \\
15 \mathrm{mg}\end{array}$} & \multicolumn{2}{|c|}{$\begin{array}{l}\text { Added at } 51 / 2 \mathrm{hrs} \\
\mathrm{Ca}^{b} \text { Apo-ca }\end{array}$} & \multirow{2}{*}{$\begin{array}{l}\text { Final Weight Ratio } \\
\mathrm{Ca} /(\mathrm{Ca}+\mathrm{Apo}-\mathrm{ca}) \\
0 / 30 \mathrm{mg}\end{array}$} & \multirow{2}{*}{$\frac{{ }_{C} \mathrm{Ca}}{0}$} \\
\hline & & $0 \mathrm{mg}$ & $15 \mathrm{mg}$ & & \\
\hline 2 & $15 \mathrm{mg}$ & $1.5 \mathrm{mg}$ & $13.5 \mathrm{mg}$ & $1.5 / 30 \mathrm{mg}$ & 5 \\
\hline 3 & $15 \mathrm{mg}$ & $15 \mathrm{mg}$ & $0 \mathrm{mg}$ & $15 / 30 \mathrm{mg}$ & 50 \\
\hline
\end{tabular}

\section{SAMPLING AND TOTAL CELL COUNTS}

To reduce sampling error, each sample was composed of five $15 \mu \mathrm{l}$ aliquots. Aliquots were removed using a using a Gibson ${ }^{\mathrm{TM}}$ pipetmann equipped with $0-200 \mu \mathrm{l}$ capacity pipet tips (West Coast Scientific, Inc.). The pipet tip was then immersed, tapered end up, halfway into a bucket of crushed ice to prevent any further cell divisions from occurring. This small sample had enough adhesion within the pipet tip to prevent its escape. To prevent settling of cells, only those flasks to be immediately sampled were removed from the shaker. All aliquots were taken within 1 minute of removing the flask from the shaker. To reduce variation, an effort was made to take all aliquots from the same area of the flask. 
Once sampled, the flask was promptly reinserted into the shaker and the next flask removed and sampled.

Each aliquot was later injected into a hemocytometer counting chamber. Cells were allowed to settle for 5 minutes before counting with a Carl Zeiss ${ }^{\text {TM }}$ light microscope equipped with a $12.5 \mathrm{X}$ ocular and a $100 \mathrm{X}$ oil immersion objective.

After the cells had settled, the total number of bacteria present in four $200 \times 200 \mu \mathrm{m}$ quadrats (volume $1.6 \times 10^{-5} \mathrm{~mm}^{3}$ ) in the hemocytometer were counted. After counting each aliquot the values were totalled and averaged to obtain the total number of cells in that sample.

To determine the number of generations that elapsed between samples within a treatment trial, the log of the total number of cells in a sample was subtracted from the log of the subsequent hour sample total number of cells and then divided by the log of 2 . The change in the number of generations between each sample of each treatment trial can be found in Appendix B.

\section{STATISTICAL ANALYSIS}

Solutions, incubation temperatures, and aeration were the same throughout the study, but certain environmental factors such as room temperature at the time of sampling, humidity, sunlight, seasonal differences, etc. were not. Therefore, the two bacterial strains were paired to minimize variation and to improve the precision with which real differences between the growth could be detected.

Because the variance of counts in some samples exceeded the mean, distributions may not have been symmetrical. Since symmetrical (normal) distributions are a necessary condition for the use of parametric tests, a non-parametric test, Wilcoxon's signed rank test (60), was used to make a probability statement concerning differences between strains within individual treatments. Previous studies have shown that the non-parametric test is 
more powerful where parametric assumptions are not met. In instances where parametric assumptions are in agreement, and the sample size is small $(<20)$, the Wilcoxon signed rank test has an efficiency of between $80 \%$ and $90 \%$.

\section{CAS AGAR}

A universal chemical assay for detection of siderophores (the CAS assay) has been developed by Schwyn and Neilands (72). CAS agar was prepared with glucose as the carbon and energy source but with and without the addition of casamino acids. The ternary complex, chrome azurol S (CAS)/ iron (III)/ hexadecyltrimethylammonium bromide (HDTMA), turns the agar blue. When bacterial growth removed the iron from the complex, the agar turns orange. CAS and HDTMA were both purchased from Fluka chemical corporation. 


\section{RESULTS}

\section{GROWTH DIFFERENCES}

To determine if a statistically significant difference was present between the growth of the two strains over a 5 hour period at each of the three iron-saturated conalbumin concentrations, we paired the strains and repeated each experiment 5 times for each of the three different iron-saturated conalbumin concentrations. Cultures were starved for iron with apoconalbumin for $51 / 2$ hours before addition of iron containing conalbumin. Samples were taken at zero time and at the end of each one hour interval over five hours for each experiment at each iron-saturated conalbumin concentration as described in Materials and Methods. In each experiment we subtracted the log of the sample value taken at the beginning of each one hour interval from the sample value taken at the end and divided this value by the $\log$ of 2 to obtain the number of generations that had occurred during each one hour interval for each experiment. Because strains were paired in each experiment, and each experiment was run 5 different times for each iron-saturated conalbumin concentration, we obtained a total of 25 paired values for each of the different ironsaturated conalbumin concentrations. We then analyzed each group of 25 paired values using the Wilcoxon signed rank test to determine if a significant difference $(p<0.05)$ existed between the growth of the two strains at any of the 3 different iron-saturated conalbumin concentrations. As shown in Table XII, the Wicoxon signed rank test showed there to be significant differences in treatment $2(5 \%$ Fe saturated) and $3(50 \%$ Fe saturated) but not 1 
(no iron). The difference in treatment 3 was more significant $(\mathrm{p}<0.01)$ than treatment 2 $(\mathrm{p}<0.05)$.

Differences in growth of the paired strains over a 5 hour period using Wilcoxon's signed rank test showed sufficient evidence to reject the null hypothesis that neither strain possessed a greater propensity for use and/or sequestering of iron from conalbumin when cultured at 5\% and 50\% iron-saturated conalbumin. Evidence was not sufficient to reject the null hypothesis in the presence of $0 \%$ iron-saturated conalbumin.

\section{TABLE XII}

SIGNIFICANCE OF DIFFERENCE OF GROWTH AS DETERMINED BY WILCOXON SIGNED RANK TEST

Treatment Growth Period (Range of times times that paired generation rates were compared $)^{\mathbf{a}}$
Treatments At Different Percent Iron Saturated Conalbumin $0 \%^{\mathrm{b}} \quad 5 \%^{\mathrm{c}} \quad 50 \%^{\mathrm{d}}$

$\begin{array}{llll}0-5 \mathrm{hrs} & \mathrm{p}>0.01 & \mathrm{p}<0.05 & \mathrm{p}<0.010\end{array}$

a make a probability statement concerning the differences between strains within treatments, generation times were compared using the Wilcoxon signed rank test. ${ }^{\mathrm{b}}$ Treatment \#1. ${ }^{\mathrm{c}}$ Treatment\#2. $\mathrm{d}$ Treatment \#3.

\section{INTERVAL COMPARISONS}

Table XIII shows the change in growth for each treatment for the 5 hour treatment period when divided into 4 intervals of 2 hours each and analyzed for differences using Wilcoxon's signed rank test (Appendix B). Results show a highly significant $(\mathrm{p}<0.01)$ growth rate advantage at 50\% iron-satuarted conalbumin for intervals 1 and 4 , a significant $(p<0.05)$ growth advantage at $5 \%$ iron-saturated conalbumin for interval 4 , and no significant $(p>0.05)$ growth advantage for any interval at $0 \%$ iron-saturated conalbumin for intervals $1-4$. 


\section{TABLE XIII}

\section{SIGNIFICANCE OF DIFFERENCE OF INTERVAL GROWTH AS DETERMINED BY WILCOXON SIGNED RANK TEST}

\section{Treatment Growth Period}

\section{Treatments At Different Percent} Iron Saturated Conalbumin

$$
5 \%^{\mathrm{c}}
$$

Interval (Times that paired generations were compared) ${ }^{\mathrm{a}} \quad 0 \%^{\mathrm{b}}$
1)

2)

3)

4)
$1 \& 2$ hrs

$2 \& 3 \mathrm{hrs}$

$3 \& 4$ hrs

$4 \& 5$ hrs

$$
\begin{aligned}
& p>0.05 \\
& p>0.05 \\
& p>0.05 \\
& p>0.05
\end{aligned}
$$

$$
\begin{aligned}
& p>0.05 \\
& p>0.05 \\
& p>0.05 \\
& p<0.05
\end{aligned}
$$

$$
\begin{aligned}
& p<0.010 \\
& p>0.05 \\
& p>0.05 \\
& p<0.010
\end{aligned}
$$

a To make a probability statement conceming the differences between strains within treatments, generations were compared using the Wilcoxon signed rank lest. ${ }^{b}$ Treatment $\# 1$. ${ }^{C}$ Treatment \#2. $\mathrm{d}$ Treatment \#3.

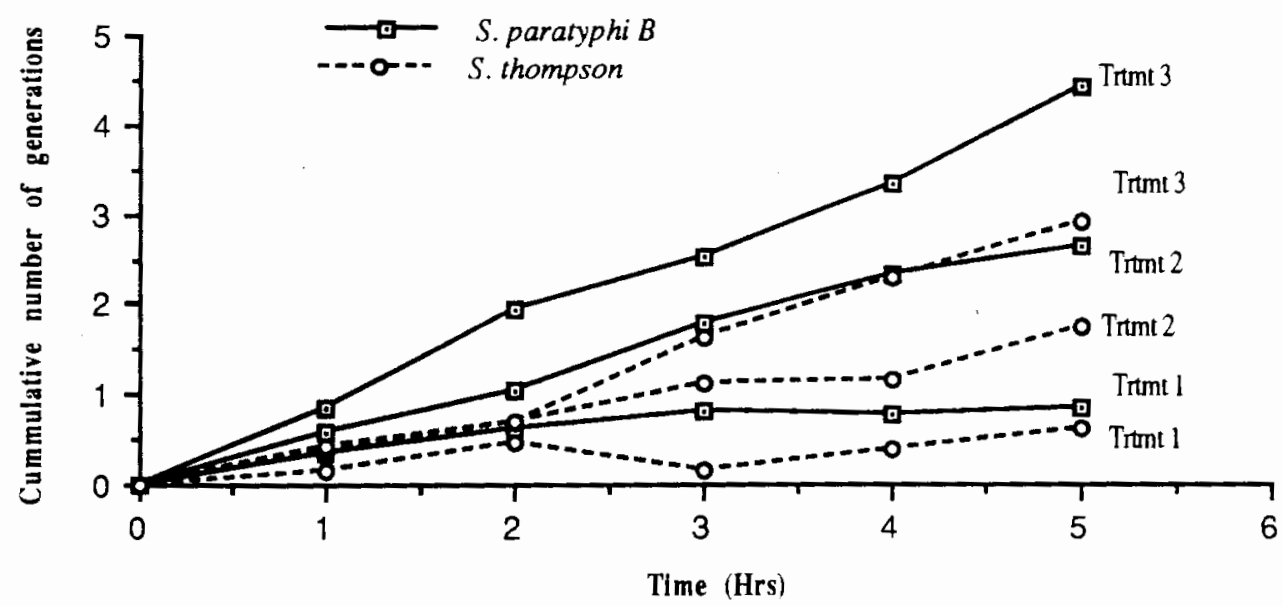

Figure 6. Growth comparison of strains. Trtmt $1.0 \%$ iron-saturated conalbumin. Trtmt $2.5 \%$ iron-saturated conalbumin Trtmt 3.50\% iron saturated conalbumin. (Data points of each graph represent the average of 5 identical experiments). 


\section{APOCONALBUMIN INDUCED BACTERIOSTASIS}

It is known that enterochelin can remove iron from conalbumin (apoconaibumin saturated with iron) (45). However, studies have demonstrated that the presence of apoconalbumin may result in the formation of enterochelin-apoconalbumin (or other siderophore complexes) that cannot be transported into the cell (58). In media where iron is limiting (reducing the efficiency of the "low affinity system") this may result in bacteriostasis after cells deplete their useable intracellular iron stores.

As shown in Figure 7, when either Salmonella paratyphi B or Salmonella thompson was grown in deferrated Medium A $(0.154 \mu \mathrm{M} \mathrm{Fe})$ without apoconalbumin, growth continued for at least 18 hours. As shown in Figure 8, when apoconalbumin was added growth ceased after 6 hours.

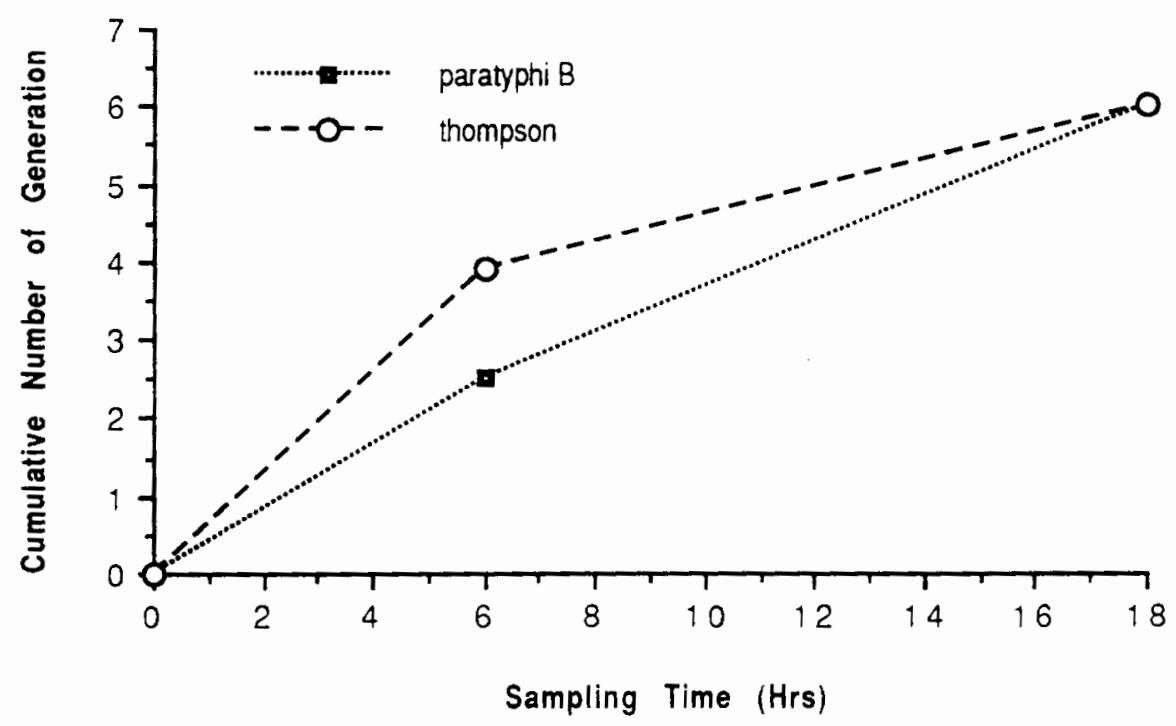

Eigure 7. Growth in deferrated Medium A without apoconalbumin added. (Data points represent the mean of 3 identical experiments). 


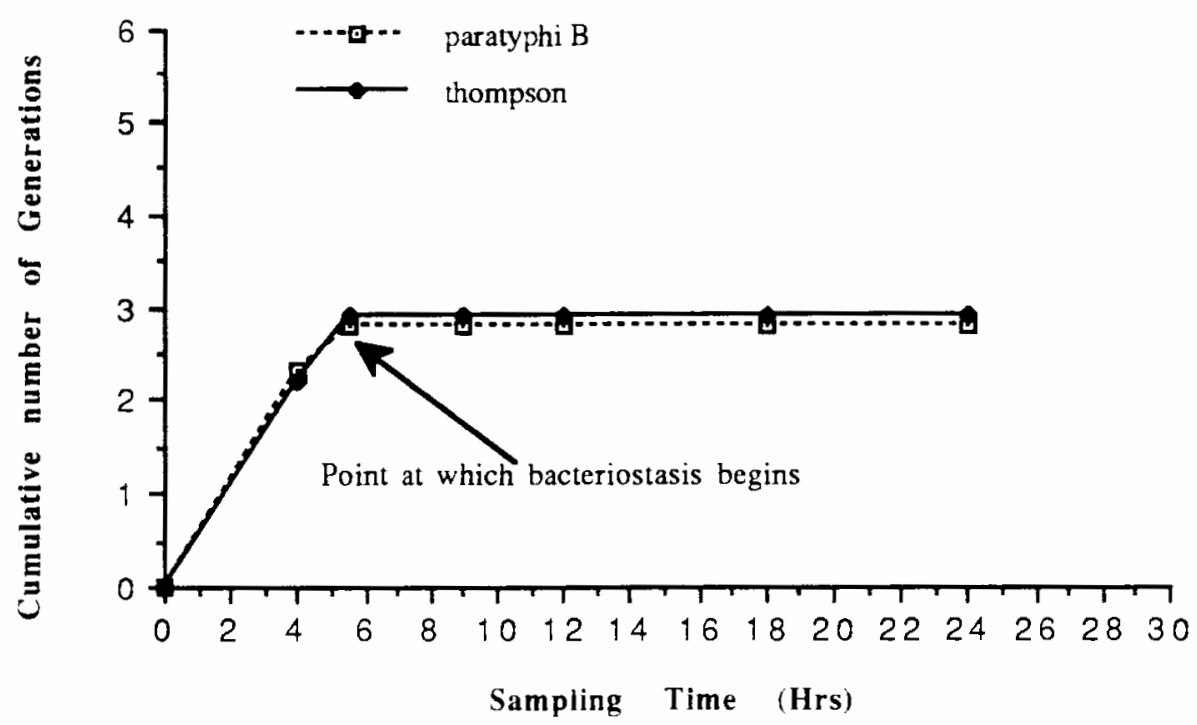

Figure 8. Growth in deferrated Medium A with apoconalbumin. (Data points represent the mean of data points from 5 identical experiments).

\section{GROWTH RESPONSE TO PHOSPHATE-BOUND-IRON AND CONALBUMIN- BOUND-IRON}

To test whether each of the strains would attain different levels of growth if given iron bound to phosphate rather than to conalbumin, iron that was bound to phosphate as a contaminant was added at an amount equivalent to that present in $1 \mathrm{mg} / \mathrm{ml}$ of $5 \%$ ironsaturated conalbumin $(1.25 \mu \mathrm{M} \mathrm{Fe})$ and $50 \%$ iron-saturated conalbumin $(12.5 \mu \mathrm{M} \mathrm{Fe})$. Each flask contained $15 \mathrm{ml}$ of deferrated Medium A and was inoculated with one of the two strains that had been starved of intracellular iron stores as described in Methods: Cell counts were made from each flask after 8 hours. Results in Figure 9 show that both strains (when given iron bound to conalbumin) attained a higher number of generations after $8 \mathrm{hrs}$ than when given iron bound to phosphate. Control flasks of iron starved cells showed no increase in cell numbers over the 8 hour incubation.

These experiments show that cells believed to be depleted of useable iron stores by the presence of apoconalbumin in the growth medium are iron limited. The addition of 
phosphate-bound iron after the apparent depletion of useable iron stores allows the cells to grow more than control flasks but less than flasks given iron bound to transferrin. The results show an increase of cell number corresponding to 1 generation for equal amounts of added phosphate iron as compared to 5 generations for $5 \%$ iron-saturated conalbumin. The addition of ten times the phosphate-bound iron only resulted in 3 generations. The $\mathrm{pH}$ in all growth flasks never dropped below pH 6.7.

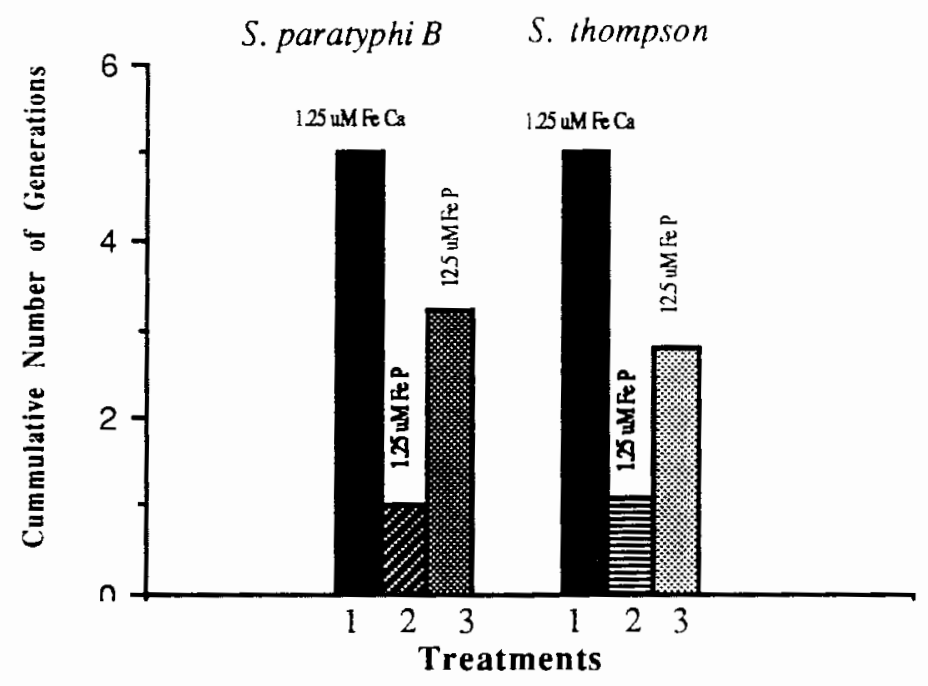

Figure 9. Comparison of final growth using phosphate-bound iron with conalbumin.

If the apoconalbumin present in the Medium A were able to absorb all the iron present on the phosphate added to the flasks, in which the iron concentration was $1.38 \mu \mathrm{M} \mathrm{Fe}$ $\left[\left(1.25 \times 10^{-6} \mathrm{M} \mathrm{Fe}\right.\right.$ added in the form of phosphate $)+(0.13 \mu \mathrm{M}$ Fe of Medium $\left.\mathrm{A})\right]$, the apoconalbumin in the flask would have been $5 \%$ iron saturated. Under these conditions growth should have then equaled the flasks to which 5\% iron saturated conalbumin was added. Thus, the results show that $1.25 \mu \mathrm{M}$ Fe added to the medium as iron phosphate does not produce the same level of growth as $1.25 \mu \mathrm{M}$ Fe added in the form of ironsaturated conalbumin. 


\section{SIDEROPHORE DETECTION}

To test for siderophore production each strain was cultured on deferrated Medium A (without apoconalbumin) containing the ternary complex CAS/iron (III)/ and HDTMA as described in Methods and Materials. Colonies that produce siderophores cause this type of agar to turn from blue to orange as a halo around the colony. When both strains were cultured on this medium for 48 hours the color of the medium remained blue. Therefore, we conclude that when grown on a basic salts medium siderophores are not produced by either strain. Siderophore tests on the supernatants from liquid cultures were consistently negative.

When strains were cultured on CAS Agar Medium supplemented with casamino acids, orange halos appeared around the colonies. Thus, we conclude that amino acids or some additional mineral present in the casamino acids may be necessary for the synthesis of siderophores by these Salmonella strains.

\section{CHANGE IN CELL MORPHOLOGY UNDER IRON STRESS}

It was consistently observed in gathering data for this investigation that cell size fluctuations and clumping occurred with both strains when cultured in Medium A containing apoconalbumin. This did not occur when celis were grown with $50 \%$ saturated conalbumin. Both strains formed clumps of 3-4 cells following 6 hours of growth with apoconalbumin (Figure 11A) that corresponded to reduced useable intracellular iron stores. The size of the clumps increased to as much as approximately 200 cells clump after 10 hours of growth (Figure 11B). The clump size was consistently larger in cultures of $S$. thompson than in S. paratyphi B. These observation might suggest that after cells become iron stressed, cells attach to other iron stressed cells to form clumps. 
All cells that were starved of useable intracellular iron stores showed a decrease in cell size going from $1 \mu \mathrm{m} \times 0.5 \mu \mathrm{m}$ at the start of the treatment to approximately $0.25 \mu \mathrm{m}$ by the end of the treatment. If the iron-stressed cells that were showing clumps were given ironsaturated conalbumin and incubated in Medium A, for 6 hours the individual cells of the clump became fusiform (1-2 $\mu \mathrm{m})$ before resuming rapid growth after $3-4$ hours.

A.

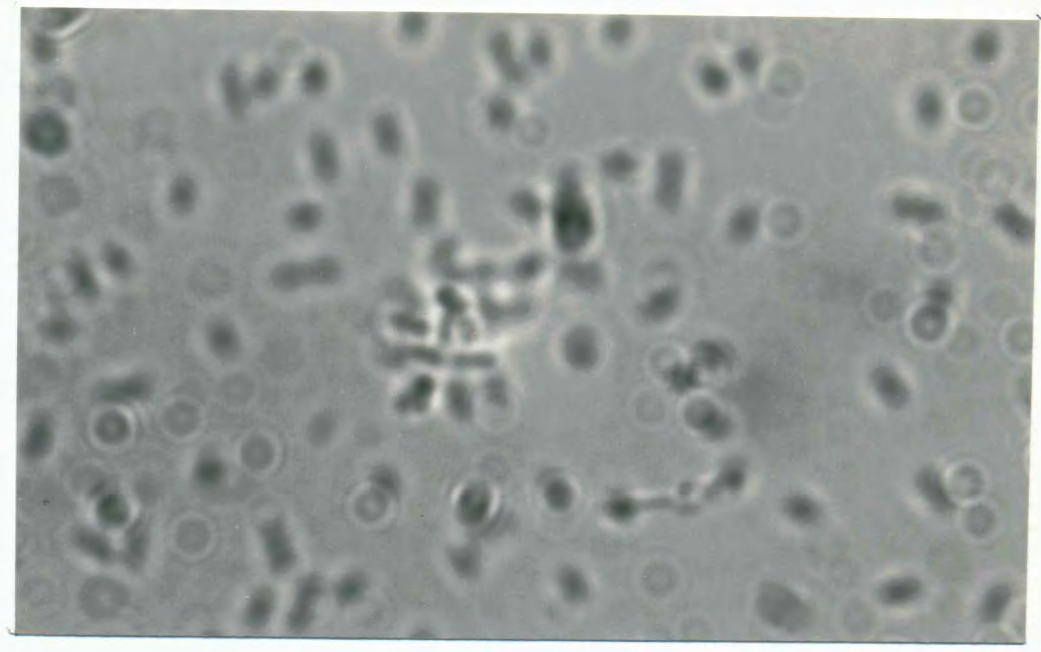

B .

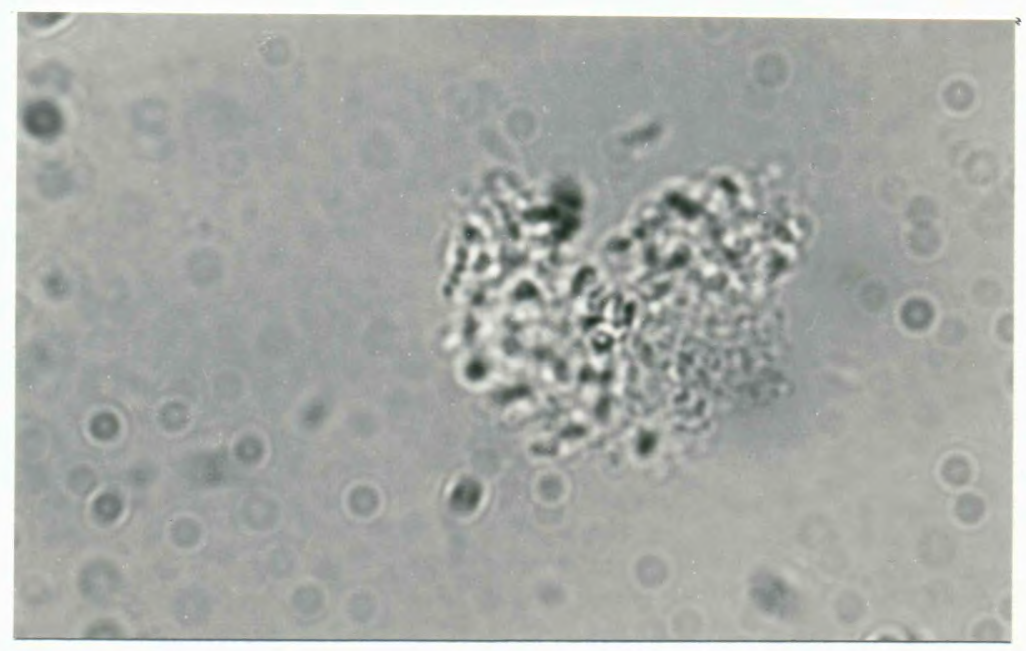

Figure 10. Clumping at 6 and 10 hours under iron stress. A. 6 hours. B. 10 hours. 


\section{DISCUSSION}

The work presented in this thesis was motivated, in part, by the findings of a Salmonella Surveillance Program established jointly by the Center for Disease Control (CDC) in Atlanta, GA and the Association of State and Territorial Epidemiologists and Laboratory Directors (ASTELD) (62). These results showed that of 269,704 positive stool isolates reported from 1968-1979, a total of 1,197 had positive blood isolates. The population segment with the highest rate of positive stool and blood cultures was that of neonates between 0 and 2 months ( 45 to 50 per million for the year 1977). This rate was 4 to 5 times higher than that of older individuals (63).

The period of elevated neonatal bacteremia correlates with a mild hyperferremic condition that arises because neonates are unable to synthesize transferrin in quantities sufficient to accomodate excess iron $(5,6)$ administered by dietary supplement. Thus, neonates given iron supplements experience increased iron transferrin saturation levels that exceed that found in normal infants over 2 months of age. Elevated levels of transferrin saturation are believed to be associated with an increase in susceptibility to Salmonella bacteremia (7). The literature does not indicate whether or not strains respond differently to increases in transferrin iron saturation. Therefore, the purpose of this study was to determine if two known strains of pathogenic Salmonella (one a stool isolate and one a wound isolate) differ in their rates of growth when conalbumin (ovotransferrin) at different levels of iron saturation was their only available iron source. 


\section{IRON SOURCE IS CONALBUMIN}

To verify that conalbumin was the only source of available iron for the strains in this study a number of preliminary tests were run. These tests verified that : a) each strain had the ability to sequester iron from conalbumin (Materials and Methods, Figure 4); b) the addition of apoconalbumin appeared to knock out the high affinity iron transport system and brought about a depletion of useable intracellular iron stores (Materials and Methods, Figure 3); and c) deferrated Medium A is able to support treatment growth while maintaining a pH above 6.4 (Materials and Methods, Figure 2).

Conalbumin-iron begins to dissociate at $\mathrm{pH} 6.0$. The controlled $\mathrm{pH}$ of the growth medium eliminated the possibility that iron dissociating from conalbumin was the iron for growth. Based on results of these preliminary tests, it was concluded that conalbumin was the only source of iron available to the strains under our experimental condition. Thus, growth differences detected after the addition of conalbumin indicate advantages only in conalbumin iron utilization and/or sequestering abilities between the strains.

\section{DIFFERENCES IN GROWTH}

Analysis of the results from growth with apoconalbumin verified that even when available iron was present in the medium, the growth of each strain did not differ ( $p$ $>0.05$ ). Results of growth with 5\% iron-saturated conalbumin and 50\% iron-saturated conalbumin after starving the cells of useable intracellular iron stores provided sufficient evidence to reject the null hypothesis that neither strain possessed a greater propensity for use and/or sequestering of iron from conalbumin. This evidence was significant $(\mathrm{p}<0.05)$ at $5 \%$ iron-saturated conalbumin and highly significant $(\mathrm{p}<0.01)$ at $50 \%$ iron-saturated conalbumin. Thus, the results confirm that $S$. paratyphi $B$ and $S$. thompson differ in their growth when conalbumin is their only available iron source. 


\section{GROWTH ADVANTAGE OF S. PARATYPHI B}

Differences between generation times of the two strains were obtained (using Wilcoxon's signed rank test) by subtracting the generation times of $S$. thompson from $S$. paratyphi B (see Appendix B). Thus, it was concluded that the significant differences in treatments \#2 (5\% iron-saturated conalbumin) and \#3 (50\% iron-saturated conalbumin) verify a growth advantage for S. paratyphi $B$. Furthermore, this advantage was found to increase as conalbumin iron saturation was raised from $5 \%$ to $50 \%$.

\section{CORRELATION OF HIGHER INCIDENCE OF BLOOD ISOLATES TO MORE EFFICIENT CONALBUMIN UTILIZATION}

The faster growth rate of $S$. paratyphi $B$ over $S$. thompson agrees with the findings discussed in the CDC and ASTELD study, in which $S$. paratyphi $B$ was found more frequently in blood isolates than S. thompson (63). Both S. paratyphi B and S. thompson can use conalbumin, but $S$ paratyphi $B$ grows faster. S. paratyphi $B$ is a human adapted organism, while $S$. thompson is an animal strain.

Transferrin-bound iron is taken up by macrophages and then released as free iron inside the cell. Because invasive strains of $S$. thompson reside in macrophages, transferrin may not serve as a direct source of iron in an infected state. Therefore, the lower efficiency of $S$. thompson to acquire iron from conalbumin, when compared to S. paratyphi B, may not be related to lower virulence.

\section{MEDLA}

In order to compare the direct effects of conalbumin on the growth of $S$. paratyphi $B$ and $S$.thompson, a deferrated low phosphate medium was used for this investigation. Results show (Figure 3) that this medium effectively reduces the efficiency of both low and high affinity iron transport systems in S. paratyphi $B$ and $S$. thompson. 
This medium with apoconalbumin is effective because it causes strains to reduce their useable intracellular iron stores. This medium when deferrated has only $0.154 \mu \mathrm{MFe}$ and thus cannot use the low affinity iron transport system. When apoconalbumin $(1 \mathrm{mg} / \mathrm{ml}$ final concentration) is added to the deferrated medium the high affinity becomes ineffective and thereby allows reduction of intracellular iron stores.

\section{SAMPLING AND COUNTING}

The minimal optical density $(660 \mathrm{~nm})$ at which growth can first be detected using a typical colorimeter, such as a Beckman Spectrophotometer. is 0.020. Deferrated low phosphate media (Medium A) used in this investigation support cell densities up to an absorbance of only 0.223 before the $\mathrm{pH}$ of the medium drops below $\mathrm{pH} 6.0$. Thus, the total number of generations attainable with these media as measured spectrophotometrically would be limited to 3.32 generations $(3.32=\log$ of $0.223-\log$ of $0.02 / \log$ of 2.0 ). This is 2 generations below the 5-6 generation requirements set forth in the study's design. Thus, alternative counting methods (such as direct counts) had to be considered.

A sutiable counting method had to: 1) monitor 5-6 generations ;2) allow detection of total counts; 3) discern between individual cells within clumps; 4) identify recently divided (but still attached) cells; and 5) permit measurement of cell sizes.

Since spread plates reveal viable but not total cell counts, and culture of strains in Medium A produced cell aggregates ("clumps"), it was felt that data obtained from spread plates would be skewed. This conclusion is based on the understanding that colonies, developed from clumps, reflect a mean that is lower than that of the actual population. Furthermore, the selective pressure resulting from the use of an iron limited plating medium might also have prevented many cells (that would have otherwise remained viable in the media) from producing colonies. Therefore, the use of spread plates was rejected. 
Because Coulter counters require large sample volumes and are inefficient at accurately distinguishing between cell aggregates with identical numbers but different masses, this method was also rejected as a feasible alternative. Thus, the final alternative, the direct count, was chosen. This method allowed for the determination of total counts, (including aggregate totals), cell size fluctuation, and between 6 and 7 generations of countable growth using the "low phosphate media" developed for this investigation.

In order that data from direct counts would accurately reflect the generations of each treatment, a decision was made to extract a total of 5 samples at each interval. This choice was based on the Critical Value Table of the Student $t$-distribution which shows that the mean standard deviation need only be multiplied by 2.5 to derive its $95 \%$ probability range at the $5 \%$ level. This multiplication factor rises or declines by $19 \%$ and $8 \%$ respectively when the sample number is increased or reduced by 2 . Thus, 5 samples were considered a compromise relative to the accuracy and time constraints set forth in this study. 


\title{
SUMMARY AND CONCLUSION
}

\author{
SUMMARY
}

The primary objective of this investigation was to determine if the growth of $S$. paratyphi $B$ and $S$. thompson varied when grown with different concentrations of conalbumin as the only available source of iron. Results revealed that growth of the strains differ significantly $(\mathrm{p}<0.05)$ at $5 \%$ iron-saturation and highly significantly $(p<0.01)$ at $50 \%$ iron saturation. In each instance, the advantage for growth favored $S$. paratyphi $B$ and was found to increase as conalbumin was raised.

The growth advantage of $S$. thompson over $S$. paratyphi $B$ is (postulated to be primarily due to a lower minimal iron concentration threshold) in S. paratyphi B. Other possibilities, such as iron transport and storage, were rejected after systematically showing that they could not individually account for this increased growth rate advantage.

The use of a low phosphate media containing apoconalbumin allows for the apparent iron starvation of useable iron stores in each strain. The reduced iron content of this medium $(0.154 \mu \mathrm{M} \mathrm{Fe})$ apparently rendered the low affinity iron transport system of each strain dysfunctional. Addition of apoconalbumin appeared to severely reduce the efficiency of each strain's high affinity iron transport system(s). These two factors allow depletion of useable iron stores for each strain and have allowed us to compare growth rates of the strains with iron bound to conalbumin as the only usable iron source. (The absence of siderophore production in this medium allowed study of the conalbumin iron in the absence of reported siderophore-conalbumin complexes). 
A reduction in cell size was consistently observed as strains became increasingly iron stressed. This reduction has been correlated with the development of cell aggregates, which appear when the flagelia of the iron stressed cells supposedly attach to one another.

\section{CONCLUSION}

$S$. paratyphi $B$ showed a significant growth advantage over $S$. thompson when conalbumin was the only available iron source. The ability of $S$. paratyphi $B$ to use iron more efficiently from conalbumin correlates with findings discussed in a 1969-1978 CDC and ASTELD study, where S. paratyphi $B$ was 3 times more frequent in blood isolates than S. thompson. Therefore, conalbumin use efficiency may be responsible, in part, for the higher incidence of $S$. paratyphi $B$ in clinical isolates involving bacteremia. 


\section{REFERENCES}

1. Jacobs, A. and M. Worwood (1974). Iron in Biochemistry and Medicine. p.2, Academic Press, NewYork.

2. Payne, S. M. (1988). Iron and Virulence in the Family Enterobacteriaceae. Critical Reviews in Microbiology 16: 81.

3. Weinberg, E. D. (1977). Microorganisms and Minerals. p. 237, Marcel Dekker, inc., New York.

4. Jacobs, A. and M. Worwood (1974). Iron in Biochemistry and Medicine. p. 424, Academic Press, New York.

5. Weinberg, E. D. (1977). Microorganisms and Minerals. p. 256. Marcel Dekker, Inc., New York.

6. Bennett, I. L. and I. W. Hook (1959). Annual Review of Medicine 10: 670.

7. Fletcher, J. and E. Goldstein (1970). British Journal of Experimental Pathology 51: 280.

8. Bullen, J. J., H. J. Rogers and G. H. Cushine (1967). Nature, London 214: 515.

9. Purifoy, D. J. and C. E. Lankford (1965). Texas Rep. Biol. Medicine 23: 637.

10. Weinberg, E. D. (1977). Microorganisms and Minerals. p. 255, Marcel Dekker, Inc., New York.

11. Winkelmann, G., D. VanderHelm, J. B. Neilands (1987). Iron Transport in Microbes, Plants and Animals. p. 20, VCH verlagsgesellschaft mbH, b-6940 Weinham.

12. Jacobs, A. and M. Worwood (1974). Iron in Biochemistry and Medicine. p. 6, Academic Press, NewYork.

13. Jacobs, A. and M. Worwood (1974). Iron in Biochemistry and Medicine. p. 5, Academic Press, NewYork.

14. Jacobs, A. and M. Worwood (1974). Iron in Biochemistry and Medicine. p. 14, Academic Press, NewYork.

15. Neilands, J.B. (1974) Microbial Iron Metabolism. A comprehensive Treatise. Academic Press, New York. 
16. Hegenauer, J. and P. Saltzman (1982). The Biochemistry and Physiology of Iron. p. 4, Elsevier Biomedical, New York.

17. Lammers, P.J. pg. 16. (1982) Ph. D. thesis, Portland State University, Portland, Oregon.

18. Lammers, P.J. pg. 17. (1982) Ph. D. thesis, Portland State University, Portland, Oregon.

19. Winkelmann, G., D. VanderHelm, J. B. Neilands (1987). Iron Transport in Microbes, Plants and Animals. p. 94, VCH verlagsgesellschaft mbH, b-6940, Weinham.

20. Winkelmann, G., D. VanderHelm, J. B. Neilands (1987). Iron Transport in Microbes, Plants and Animals. p. 210, VCH verlagsgesellschaft mbH, b-6940, Weinham.

21. Payne, S. M. (1988). Iron and Virulence in the Family Enterobacteriaceae. Critical Reviews in Microbiology 16: 90.

22. Winkelmann, G., D. VanderHelm. J. B. Neilands (1987). Iron Transport in Microbes, Plants and Animals. p. 138, VCH verlagsgeselischaft mbH, b-6940, Weinham.

23. Lammers, P.J. pg. 21. (1982) Ph. D. thesis, Portiand State University, Portland, Oregon.

24. National Research Council (1979). Iron. p. 44, University Park Press, Baltimore.

25. Winkelmann, G., D. VanderHelm. J. B. Neilands (1987). Iron Transport in Microbes, Plants and Animals. p. 11, VCH verlagsgesellschaft mbH, b-6940, Weinham.

26. Winkelmann, G., D. VanderHelm, J. B. Neilands (1987). Iron Transport in Microbes, Plants and Animals. p. 33, VCH verlagsgesellschaft mbH, b-6940, Weinham.

27. Payne, S. M. (1988). Iron and Virulence in the Family Enterobacteriaceae. Critical Reviews in Microbiology 16: 88.

28. Winkelmann, G., D. VanderHelm, J. B. Neilands (1987). Iron Transport in Microbes, Plants and Animals. p. 69, VCH verlagsgesellschaft mbH, b-6940, Weinham.

29. Crosa, J. H. (1989). Genetics and Molecular Biology of Siderophore-Mediated Iron Transport in Bacteria. Microbiological Reviews 53: 523.

30. Mickelsen, P. A. and P. F. Sparling (1981). Ability of Neisseria gonorrhoeae, Neisseria meningitidis, and commensal Neisseria species to obtain iron from transferrin and iron compounds. Infect. Immun. $33: 555$. 
31. Payne, S. M. (1988). Iron and Virulence in the Family Enterobacteriaceae. Critical Reviews in Microbiology 16: 90.

32. Martinez, J. L., E. Cercenado, F. Baquero, J. C. Perez-Diaz and A. DelgadoIribarren (1987). Incidence of aerobactin production in Gram-negative hospital isolates. FEMS Microbiology Letters $43: 352$.

33. McDougall, S. and J. B. Neilands (1984). Plasmid- and chromosome-coded aerobactin synthesis in enteric bacteria: insertion sequences flank operon in plasmid-mediated system. Journal of Bacteriology 159:300.

34. Colonna, B., and M. Nicoletti, P. visca, M. Casalino, P. Valenti, and F. Maimone (1985). Composite ISI Elements Encoding Hydroxamate-Mediated Iron Uptake in FIme Plasmids from Epidemic Salmonella spp. Journal of Bacteriology 162 : 307.

35. Williams, P. H., N. H. Carbonetti (1985). Iron. Siderophores, and the Pursuit of Virulence: Independence of Aerobactin and Enterochelin Iron Uptake Systems in Escherichia coli. Infection and Immunity 51: 942.

36. Williams, P. H., N. H. Carbonetti (1985). Iron, Siderophores, and the Pursuit of Virulence: Independence of Aerobactin and Enterochelin Iron Uptake Systems in Escherichia coli. Infection and Immunity 51: 946.

37. Mandell, G. L., R. G. Douglas Jr., J. E. Bennett (1990). Principles and Practice of Infectious Diseases. p. 1663, Churchill Livingstone, New York.

38. Jacobs, A. and M. Worwood (1974). Iron in Biochemistry and Medicine. p. 14, Academic Press, NewYork.

39. Jacobs, A. and M. Worwood (1974). Iron in Biochemistry and Medicine. p. 43, Academic Press, NewYork.

40. Winkelmann, G., D. VanderHelm, J. B. Neilands (1987). Iron Transport in Microbes, Plants and Animals. p. 69, VCH verlagsgesellschaft mbH, b-6940, Weinham.

41. Jacobs, A. and M. Worwood (1974). Iron in Biochemistry and Medicine. p. 347, Academic Press, NewYork.

42. Aisen, P. and A. Leibman (1968). Biochemical and Biophysical Research Communications. $30: 407$.

43. Warner, R. C. and I. Weber (1953). The Metal Combining Properties of Conalbumin. Journal of the American Chemical Society $75: 5096$.

44. Warner, R. C. and I. Weber (1953). The Metal Combining Properties of Conalbumin. Journal of the American Chemical Society $75: 5097$.

45. Winkelmann, G., D. VanderHelm, J. B. Neilands (1987). Iron Transport in Microbes, Plants and Animals. p. 32, VCH verlagsgesellschaft mbH, b-6940, Weinham. 
46. Bullen, J. J., H. J. Rogers and G. H. Cushine (1967). Nature, London 214 : 515.

47. Fletcher J. and E. Goldstein (1970). British Journal of Experimental Pathology 51 : 280.

48. Purifoy, D. J. and C. E. Lankford (1965). Texas Rep. Biological Med. $23: 637$.

49. Bennett, I. L. and E. W. Hook (1959). Annual Review of Medicine 10:670.

50. Black, New England Journal of Medicine $262: 864$.

51. Weinberg, E. D. (1977). Microorganisms and minerals. p. 256, Marcel Dekker, Inc., New York.

52. Mandell, G. L., R. G. Douglas Jr., J. E. Bennett (1990). Principles and Practice of Infectious Diseases. p. 1700, Churchill Livingstone, New York.

53. Joklik, W. K., H. P. Willett, D. B. Amos and C. M. Wifert (1988). Zinsser Microbialogy. p. 475, Appleton and Lange, Norwalk, Conn.

54. Joklik, W. K., H. P. Willett, D. B. Amos and C. M. Wifert (1988). Zinsser Microbiology. $\quad$ p. 475, Appleton and Lange, Norwalk. Conn.

55. Mandell, G. L., R. G. Douglas Jr., J. E. Bennett (1990). Principles and Practice of Infectious Diseases. p. 1705, Churchill Livingstone, New York.

56. Buchanan, R. E. and N. E. Gibbons (1974). Bergey's Mannual of Determinative Bacteriology Eighth Edition. p. 298, The Williams and Wilkins Company, Baltimore.

57. Waring, W. S. and C. H. Werkman (1942). Growth of Bacteria in an Iron-Free Medium. Arch. Biochem. and Biophys. 1: 306.

58. Williams, P. H., N. H. Carbonetti (1985). Iron, Siderophores, and the Pursuit of Virulence: Independence of Aerobactin and Enterochelin Iron Uptake Systems in Escherichia coli. Infection and Immunity 51: 946.

59. Elliott, J.M. (1973). Some Methods for the Statistical Analysis of Samples of Benthic Invertebrates. p. 70, Freshwater Biological Association Scientific Publication No. 25, 1971.

60. Snedecor, G.W. and W. G. Cochran (1967). Statistical Methods Sixth Edition. p. 128, The Iowa State University Press, Ames, Iowa.

61. Ostle, B. and L. C. Malone (1988). Statistics in Research. Iowa State University Press, Ames. p. 92.

62. Blaser, M. J. and R. A. Feldman (1981). Salmonella Bacteremia: Reports to the Centers for Disease Contraol, 1968-1979. The Journal of Infectious Diseases. $143: 743$. 
63. Blaser, M. J. and R. A. Feldman (1981). Salmonella Bacteremia: Reports to the Centers for Disease Control, 1968-1979. The Journal of Infectious Diseases. $143: 744$.

64. Snedecor, G. W. and W. G. Cochran (1989). Statistical Methods, Eighth Edition. lowa State University Press, Ames. 140-141.

65. Ostle, B. and L. C. Malone (1988). Statistics in Research. Iowa State University Press, Ames. 161-162, 633.

66. Neilands, J.B. (1974) Microbial Iron Metabolism, A Comprehensive Treatise. Academic Press, New York. p.

67. Neilands, J.B. (1974) Microbial Iron Metabolism, A comprehensive Treatise. Academic Press, New York. p.

68. Gerhardt, P and et. al. (1981). Methods in bacteriology.

69. Mellencamp, M. W., M. A. McCabe and I. Kochan (1981). The Growth-promoting Effect of Bacterial Iron for Serum-exposed Bacteria. Immunology 43:483.

70. McIntosh, M. a. and C. F. Earhart (1977). Coordinate Regulation by Iron of the Synthesis of Phenolate Compounds and Three Outer Membrane Proteins in Escherichia coli. Journal of Bacteriology. 131:331-339

71. Pollack, J. R. and J. B. Neiland (1970). Enterobactin, an Iron Transport Compound From Salmonella Typhimurium. Biochem \& Biophys. Res. Comm. 38:989

72. Schwyn, B. and Neilands, J. B. (1987). Universal Chemical Assay for the Detection and Determination of Siderophores. Analytical Biochemisry. 160:47-56

73. Jacobs, A. and M. Worwood (1974). Iron in Biochemistry and Medicine. p. 41, Academic Press, New York.

74. Corbridge, D. E. C., (1985) Phosphorus. Elsevier, New York, N.Y. 140. 


\section{APPENDIX A}

PROCEDURE FOR DEFERRATION OF MEDIA SOLUTIONS 


\section{APPENDIX A \\ PROCEDURE FOR DEFERRATION OF MEDIA SOLUTIONS ${ }^{\mathrm{a}}$}

1) Add about $5 \mathrm{mg}$. of crystalline 8-hydroxquinoline (dissolved in $1 \mathrm{ml}$. of chloroform) to a $1000 \mathrm{ml}$ separatory funnel containing $150 \mathrm{ml}$ of the solution to be deferrated.

2) Shake the funnel vigorously for one minute and then allow to stand for five minutes.

3) Add about $3 \mathrm{ml}$. more chloroform and shake vigorously for one minute before rotating for about a half minute to cause the droplets of chloroform to coalesce and separate at the bottom of the funnel.

4) At this point it will be noted that the chloroform is either black if ferrous iron is present, or dark green in the presence of ferric iron.

5) The chloroform layer is now drawn off and the solution again washed twice repeating steps 3-5, using $3 \mathrm{ml}$. portions of chloroform.

6) The extraction procedure in steps 1-6 is again repeated, but with $5 \mathrm{mg}$ portions of solid 8-hydroxyquinoline being added directly to the funnel (rather than to $1 \mathrm{ml}$ of chloroform) before shaking vigorously into the chloroform saturated aqueous solution. The iron complexes are then washed out until they are no longer formed.

8) A total of three extractions are necessary to reduce the residual iron of a standard buffering solution (such as M-9) to approximately $25 \%$ of its original content.

9) Once deferrated, the solution is autoclaved (to remove any excess chloroform) and stored at $4^{\circ} \mathrm{C}$ until use.

${ }^{\mathrm{a}}$ This is a modification of the procedure of Waring and Werkman (57). 


\section{APPENDIX B}

DATA AND ANALYSIS 


\section{APPENDIX B}

\section{DATA AND ANALYSIS}

\section{TREATMENT \#1: COMPARISON OF GENERATIONS $0-5$ HRS}

Hrs After ** Generations/hr

Add. of $\mathrm{Ca}$ paratyphi thompson Diff Rank Positive Negative

\begin{tabular}{|c|c|c|c|c|c|c|}
\hline $1 a$ & -0.04 & 0.06 & -0.1 & 3 & & 3 \\
\hline $1 \mathrm{~b}$ & 0.6 & 0.47 & 0.13 & 4.5 & 4.5 & \\
\hline $1 c$ & 0.26 & 0.43 & -0.17 & 6 & & 6 \\
\hline$I d$ & 0.92 & 0.9 & 0.52 & 15.5 & 15.5 & \\
\hline 10 & 0.09 & -0.5 & 0.59 & 18 & 18 & \\
\hline $2 a$ & 0.11 & 0.58 & -0.47 & 14 & & 14 \\
\hline $2 b$ & 0.08 & 0.6 & -0.52 & 15.5 & & 15.5 \\
\hline $2 c$ & 0.57 & -0.04 & 0.61 & 20 & 20 & \\
\hline $2 d$ & 0.32 & 0.6 & -0.28 & 10.5 & & 10.5 \\
\hline $2 \bullet$ & 0.28 & -0.32 & 0.6 & 19 & 19 & \\
\hline $3 a$ & 0.21 & 0.02 & 0.19 & 7 & 7 & \\
\hline $3 \mathrm{~b}$ & 0.26 & -0.08 & 0.34 & 13 & 13 & \\
\hline $3 c$ & 0.29 & 0.57 & -0.28 & 10.5 & & 10.5 \\
\hline $3 d$ & 0.02 & -0.52 & 0.54 & 17 & 17 & \\
\hline $3 a$ & 0.05 & -1.41 & 1.46 & 24 & 24 & \\
\hline $4 a$ & 0.39 & 0.16 & 0.23 & 8 & 8 & \\
\hline $4 b$ & 0.27 & 0.02 & 0.25 & 9 & 9 & \\
\hline $4 c$ & 0.13 & 0.26 & -0.13 & 4.5 & & 4.5 \\
\hline $4 d$ & -0.31 & -1.14 & 0.83 & 21 & 21 & \\
\hline 49 & -0.64 & 1.73 & -2.37 & 25 & & 25 \\
\hline $5 a$ & 0.08 & -0.97 & 1.05 & 1.5 & & 1.5 \\
\hline $5 \mathrm{~b}$ & -0.31 & -0.23 & -0.08 & 1.5 & & 1.5 \\
\hline $5 c$ & 0.29 & -0.04 & 0.33 & 12 & 12 & \\
\hline $5 d$ & -0.75 & 0.7 & -1.45 & 23 & & 23 \\
\hline \multirow[t]{2}{*}{$5 e$} & 0.25 & -0.73 & 0.98 & 22 & 22 & \\
\hline & & & & TOt $=$ & 210 & $115 *$ \\
\hline
\end{tabular}




\section{TREATMENT \#1: COMPARISON OF GENERATIONS 0 - 2 HRS}

Hrs After Generations/hr

Add. of Ca paratyphi thompson Diff Rank Positive Negative

$\begin{array}{lrrrrrrr}1 a & -0.4 & 0.06 & -0.1 & 1 & & 1 \\ 1 b & 0.6 & 0.47 & 0.13 & 2 & 2 & \\ 1 c & 0.26 & 0.43 & -0.17 & 3 & & 3 \\ 1 d & 0.92 & 0.4 & 0.52 & 6.5 & 6.5 & \\ 1 a & 0.09 & -0.5 & 0.59 & 8 & 8 & -5 \\ 2 a & 0.11 & 0.58 & -0.47 & 5 & & -6.5 \\ 2 b & 0.08 & 0.6 & -0.52 & 6.5 & & 10 & -4 \\ 2 c & 0.57 & -0.04 & 0.61 & 10 & & 9 & \\ 2 a & 0.32 & 0.6 & -0.28 & 4 & & \\ 2 a & 0.28 & -0.32 & 0.6 & 9 & & & \end{array}$

* Not significant $(\mathrm{p}>0.05)$

\section{TREATMENT \#1: COMPARISON OF GENERATIONS 1-3 HRS}

Hrs After

Add. of Ca paratyphi thompson Diff Rank Positive Negative

$2 a$

$2 \mathrm{~b}$

$2 \mathrm{c}$

$2 d$

20

$3 \mathbf{a}$

$3 b$

$3 c$

$3 d$

3 e
0.08

$\begin{array}{ll}0.58 & -0.47\end{array}$

0.57

$0.6 \quad-0.52$

0.32

$-0.04$

0.6

0.61

$0.28 \quad-0.32$

0.21

0.02

0.26

$-0.08$

0.29

0.57

$-0.28$

0.6

0.19

0.34

$-0.28$

$0.02-0.52$

0.54

$0.05 \quad-1.41$

1.46
4

5

8

2.5

7

1

3

2.5

2.5

6

9 


\section{TREATMENT \# 1: COMPARISON OF GENERATIONS 2-4 HRS}

Hrs After Generations/hr

Add. of $\mathrm{Ca}$ paratyphi thompson Diff $\underline{\text { Rank Positive Negative }}$

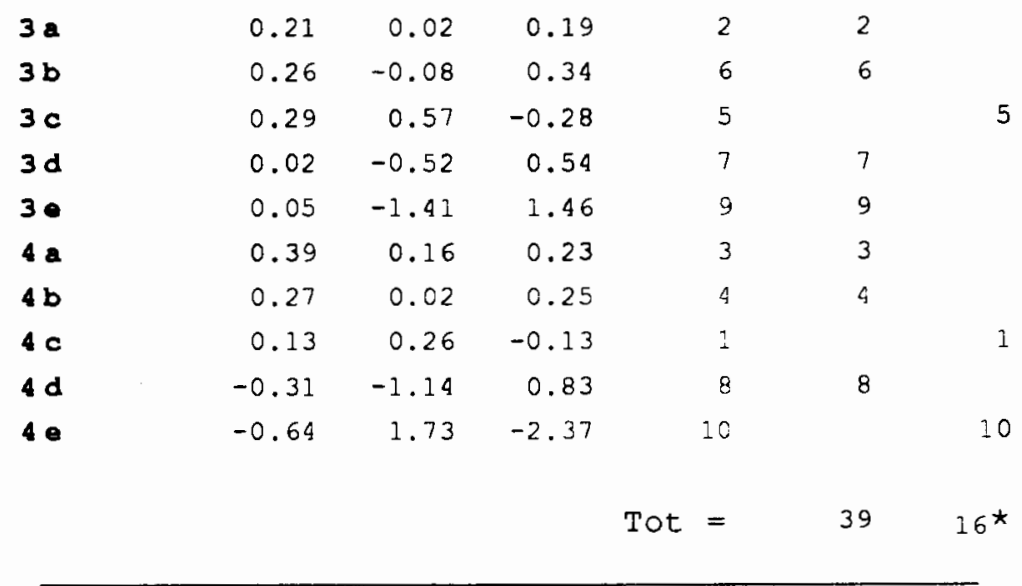

* Not significant $(p>0.05)$

TREATMENT \#1: COMPARISON OF GENERATIONS 3-5 HRS

Hrs After Generations/hr

Add. of Ca paratyphi thompson Diff Rank Positive Negative

$\begin{array}{lrrrrrr}\mathbf{4 a} & 0.39 & 0.16 & 0.23 & 3 & 3 & \\ \mathbf{4 b} & 0.27 & 0.02 & 0.25 & 4 & 4 & \\ \mathbf{4 c} & 0.13 & 0.26 & -0.13 & 2 & & 2 \\ \mathbf{4 d} & -0.31 & -1.14 & 0.83 & 6 & 6 & 10 \\ \mathbf{4 e} & -0.64 & 1.73 & -2.37 & 10 & & \\ \mathbf{5 a} & 0.08 & -0.97 & 1.05 & 8 & 8 & 1 \\ \mathbf{5 b} & -0.31 & -0.23 & -0.08 & 1 & & \\ \mathbf{5 c} & 0.29 & -0.04 & 0.33 & 5 & 5 & \\ \mathbf{5 d} & -0.75 & 0.07 & -1.45 & 9 & & \\ \mathbf{5 e} & 0.25 & -0.73 & 0.98 & 7 & 7\end{array}$

* Not significant $(\mathrm{p}>0.05)$ 


\section{TREATMENT \#2: COMPARISON OF GENERATIONS 0 - 5 HRS}

\section{Hrs After Generations/hr}

Add of Ca paratyphi thompson Diff Rank Positive Negative

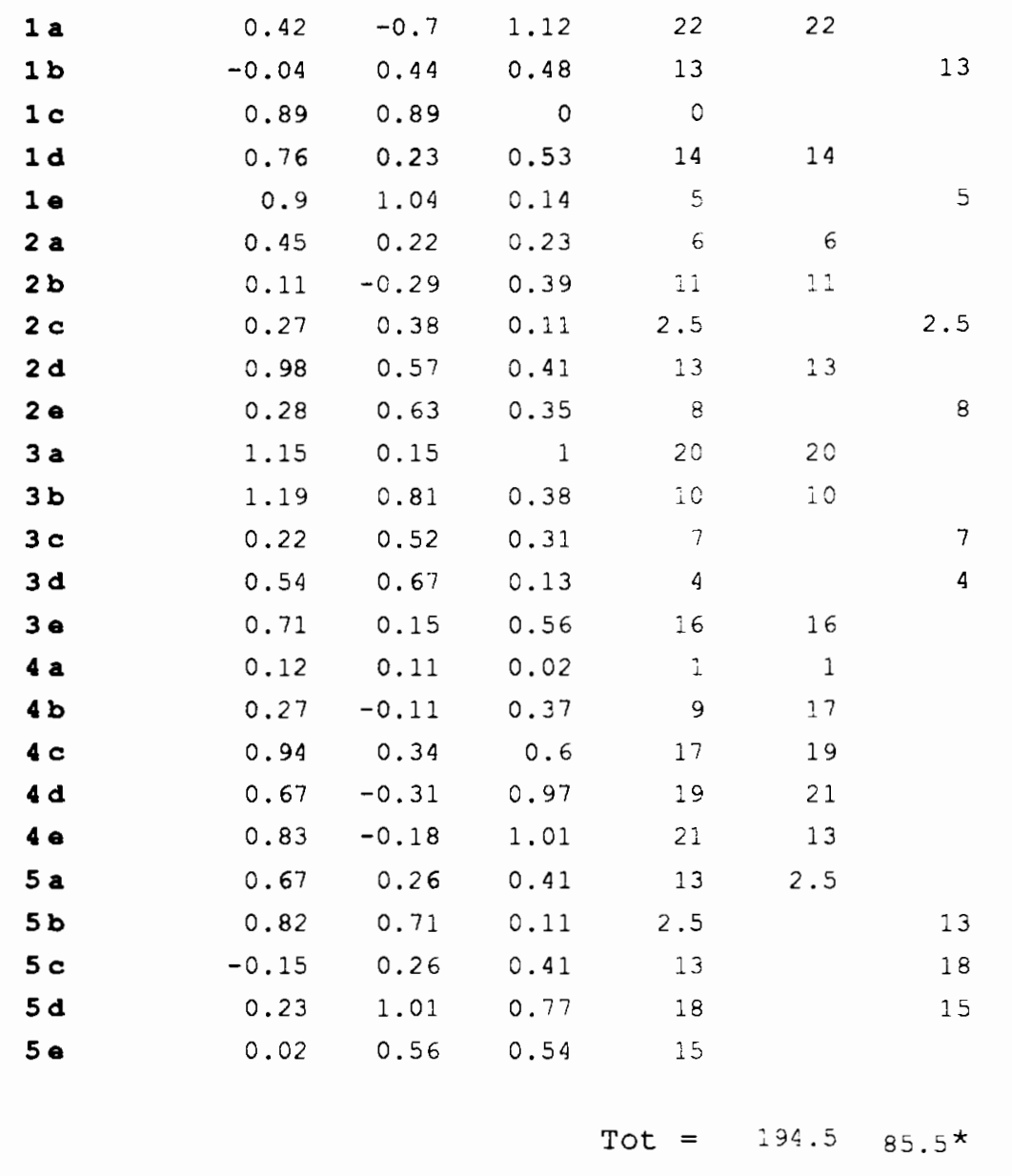

* Significant $(\mathrm{p}<0.05)$ 


\section{TREATMENT \#2: COMPARISON OF GENERATIONS 0 - 2 HRS}

Hrs After Generations/hr Add. of Ca paratyphi thompson Diff Rank Positive Negative

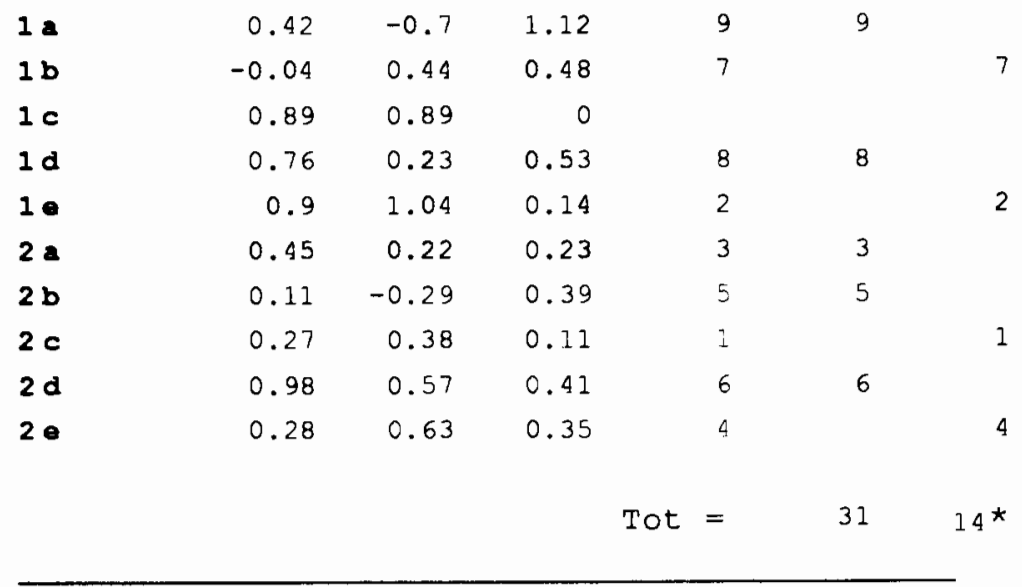

*Not significant $(\mathrm{p}>0.05)$

TREATMENT \#2: COMPARISON OF GENERATIONS 1 - 3 HRS

Hrs After Generations/hr

Add. of $\mathrm{Ca}$ paratyphi thompson Diff Rank Positive Negative

$\begin{array}{lrrrrrr}2 \mathbf{a} & 0.45 & 0.22 & 0.23 & 7 & 3 & \\ \mathbf{2 b} & 0.11 & -0.29 & 0.39 & 1 & 7 & \\ \mathbf{2 c} & 0.27 & 0.38 & 0.11 & 8 & & 1 \\ \mathbf{2 d} & 0.98 & 0.57 & 0.41 & 5 & 8 & \\ \mathbf{2 a} & 0.28 & 0.63 & 0.35 & 10 & & 5 \\ 3 \mathbf{a} & 1.15 & 0.15 & 1 & 6 & 10 & \\ 3 \mathbf{b} & 1.19 & 0.81 & 0.38 & 4 & 6 & \\ 3 \mathbf{c} & 0.22 & 0.52 & 0.31 & 2 & & 2 \\ 3 \mathbf{d} & 0.54 & 0.67 & 0.13 & 9 & & 9\end{array}$

Tot 43 12*




\section{TREATMENT \#2: COMPARISON OF GENERATIONS 2-4 HRS}

Hrs After Generations/hr

Add. of Ca Daratyphi thompson Diff Rank Positive Negative

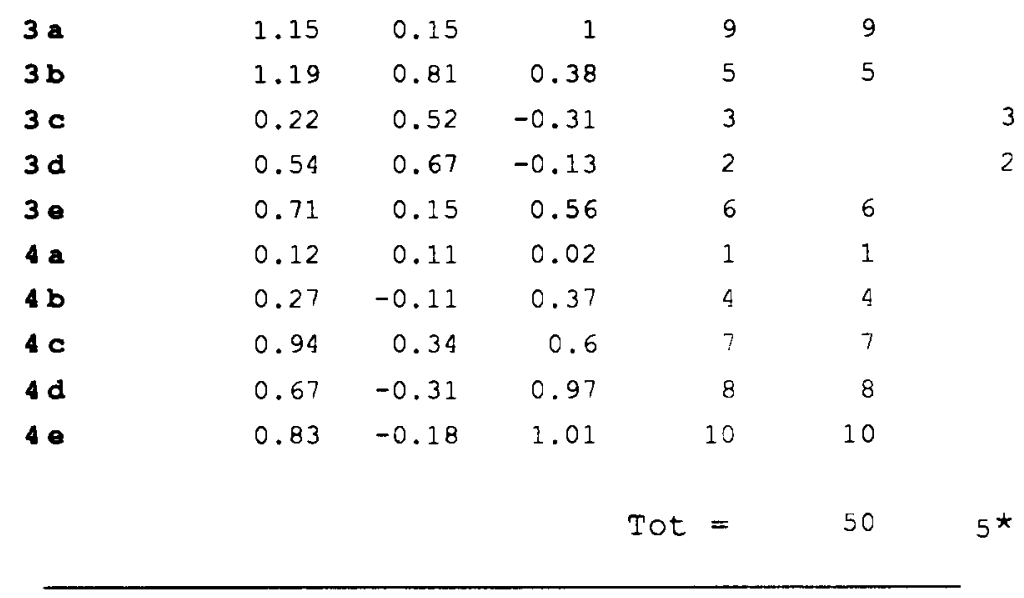

* Significant $(\mathrm{p}<0.05)$

TREATMENT \#2: COMPARISON OF GENERATIONS 3 - 5 HRS

Hrs After Generations/hr

Add. of $\mathrm{Ca}$ paratyphi thompson Diff Rank Positive Negative

\begin{tabular}{|c|c|c|c|c|c|c|}
\hline $4 a$ & 0.12 & 0.11 & 0.02 & 1 & $i$ & \\
\hline $4 b$ & 0.27 & -0.11 & 0.37 & 3 & 3 & \\
\hline $4 c$ & 0.94 & 0.34 & 0.6 & 7 & 7 & \\
\hline $4 d$ & 0.67 & -0.31 & 0.97 & 9 & 9 & \\
\hline $4 e$ & 0.83 & -0.18 & 1.01 & 10 & 10 & \\
\hline $5 a$ & 0.67 & 0.26 & 0.41 & 4.5 & 4.5 & \\
\hline $5 \mathrm{~b}$ & 0.82 & 0.71 & 0.11 & 2 & 2 & \\
\hline $5 c$ & -0.15 & 0.26 & 0.41 & 4.5 & & 4.5 \\
\hline $5 d$ & 0.23 & 1.01 & 0.77 & 8 & & 8 \\
\hline \multirow[t]{2}{*}{$5 e$} & 0.02 & 0.56 & 0.54 & 6 & 6 & \\
\hline & & & & $t=$ & 42.5 & $12.5^{\star}$ \\
\hline
\end{tabular}




\section{TREATMENT \#3: COMPARISON OF GENERATIONS 0 - 5 HOURS}

Hrs After Generations/hr

Add of Ca paratyphi thompson Diff Rank Positive Negative

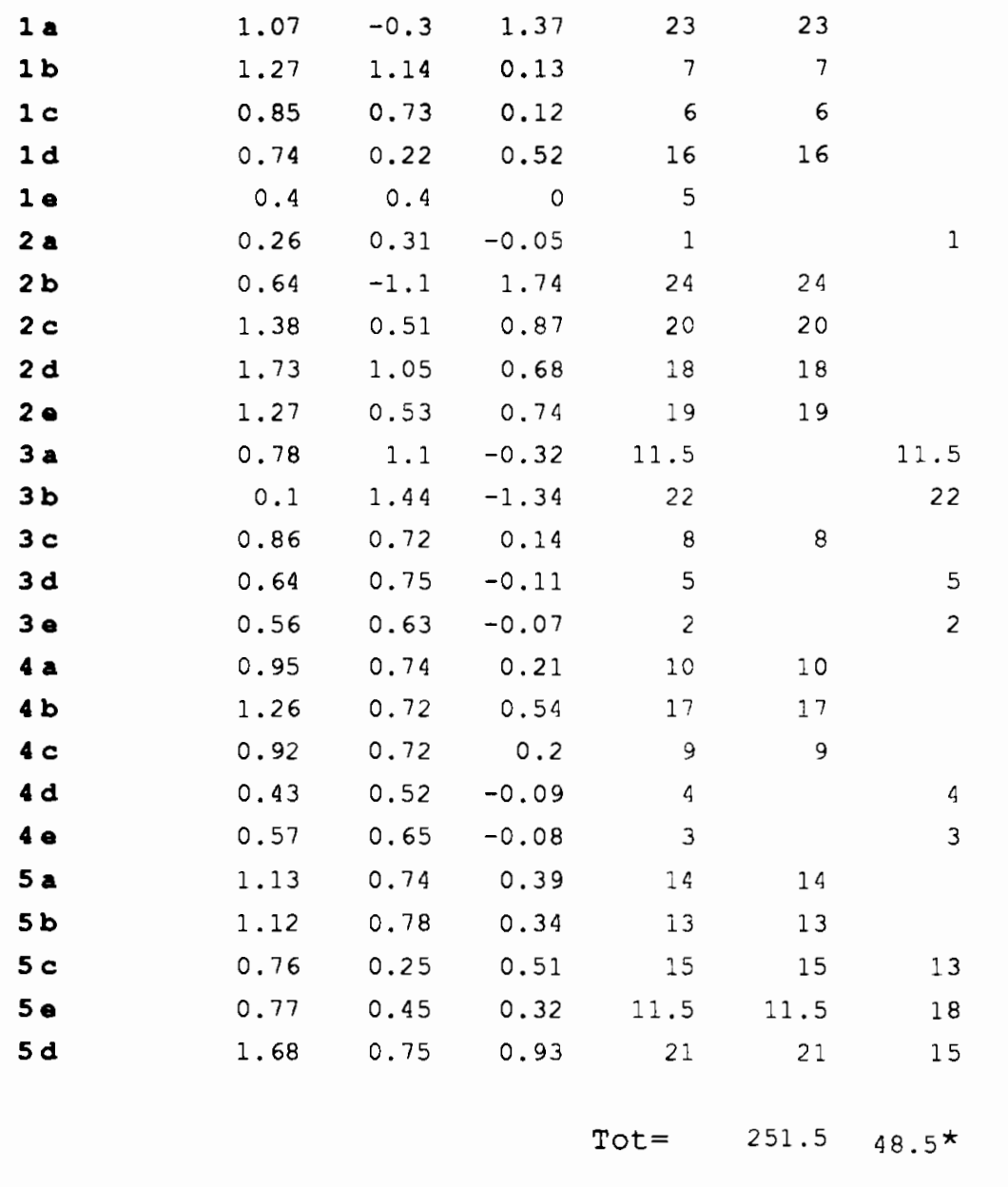

* Significant $(\mathrm{p}<0.01)$ 


\section{TREATMENT \#3: COMPARISON OF GENERATIONS $\quad 0$ - 2 HRS}

Hrs After Generations/hr

Add of Ca paratyphi thompson Diff Rank Positive Negative

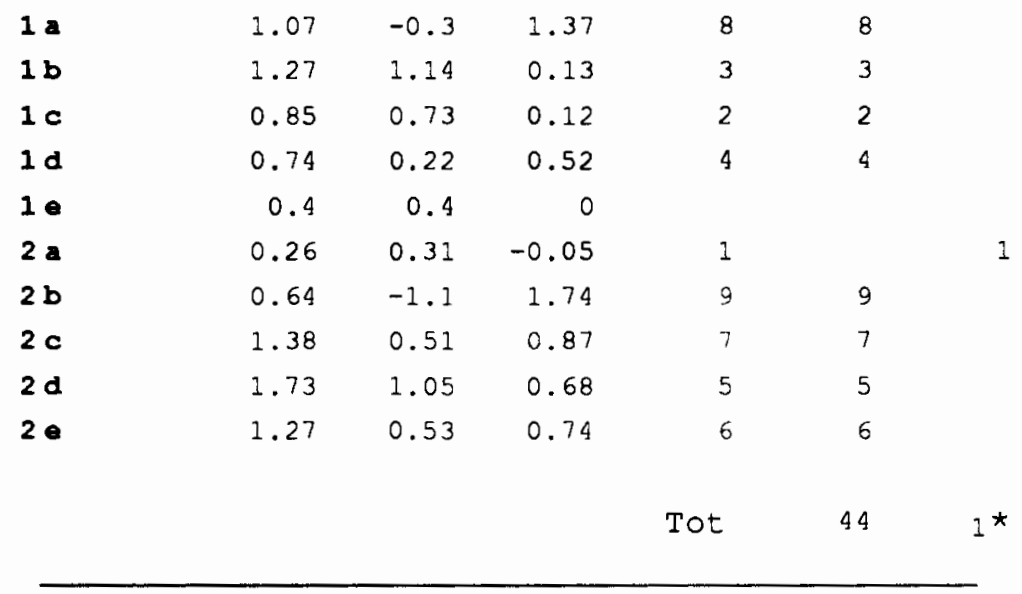

* Significant $(p>0.01)$

\section{TREATMENT \#3: COMPARISON OF GENERATIONS 3 - 5 HRS}

Hrs After Generations/hr

Add. of Ca paratyphi thompson Diff $\underline{\text { Rank Positive Negative }}$

$\begin{array}{lrrrrrr}\mathbf{4 a} & 0.95 & 0.74 & 0.21 & 4 & 4 \\ \mathbf{4 b} & 1.26 & 0.72 & 0.54 & 9 & 9 & \\ \mathbf{4 c} & 0.92 & 0.72 & 0.2 & 3 & 3 & \\ \mathbf{4 d} & 0.43 & 0.52 & -0.09 & 2 & & 1 \\ \mathbf{4 a} & 0.57 & 0.65 & -0.08 & 1 & & 7 \\ \mathbf{5 a} & 1.13 & 0.74 & 0.39 & 7 & 6 \\ \mathbf{5 b} & 1.12 & 0.78 & 0.34 & 6 & 8 \\ \mathbf{5 c} & 0.76 & 0.25 & 0.51 & 8 & 5 \\ \mathbf{5 d} & 0.77 & 0.45 & 0.32 & 5 & 10\end{array}$

Tot 52 *




\section{TREATMENT \#3: COMPARISON OF GENERATIONS 1-3 HRS}

Hrs After Generations/Hr

Add. of $\mathrm{Ca}$ paratyphi hompson Diff Rank Positive Negative

\begin{tabular}{|c|c|c|c|c|c|c|}
\hline $2 \mathrm{a}$ & 0.26 & 0.31 & -0.05 & 1 & & \\
\hline $2 b$ & 0.64 & -1.1 & 1.74 & 10 & 10 & \\
\hline $2 c$ & 1.38 & 0.51 & 0.87 & 8 & 8 & \\
\hline $2 d$ & 1.73 & 1.05 & 0.68 & 6 & 6 & \\
\hline 2 & 1.27 & 0.53 & 0.74 & 7 & 7 & \\
\hline $3 \mathrm{a}$ & 0.78 & 1.1 & -0.32 & 5 & & \\
\hline $3 b$ & 0.1 & 1.44 & -1.34 & 9 & & \\
\hline $3 c$ & 0.86 & 0.72 & 0.14 & 4 & 4 & \\
\hline $3 d$ & 0.64 & 0.75 & -0.11 & 3 & & 3 \\
\hline $3 e$ & 0.56 & 0.63 & -0.07 & 2 & & \\
\hline
\end{tabular}

* Not significant $(p>0.05)$

TREATMENT \#3: COMPARISON OF GENERATIONS 2-4 HRS

Hrs After Generations/hr

Add. of Ca paratyphi thompson Diff Rank Positive Negative

$3 \mathbf{a}$

$3 \mathbf{b}$

$3 \mathrm{c}$

$3 d$

$3 e$

$4 \mathrm{a}$

$4 \mathrm{~b}$

$4 c$

$4 d$

40
0.78

0.1

0.86

0.64

0.56

0.95

1.26

0.92

0.43

0.57

$$
-0.32
$$

$-1.34$

0.72

0.75

0.63

0.74

0.72

0.72

0.52

0.65

0.14

$-0.11$

$-0.07$

0.21

0.54

0.2

$-0.09$

$-0.08$

Tot
8

10

5

4

1

7

9

6

3

2 